\title{
ARQUEOLOGÍA HISTÓRICA DE QUITO: EL CASO DEL CONVENTO DE SANTO DOMINGO
}

\author{
Historical Archaeology of Quito: The Case of the Santo Domingo Convent
}

\section{VICTORIA DOMÍNGUEZ *}

Fecha de recepción: 20 de julio de 2020 - Fecha de aprobación: 15 de junio de 2021

\section{Resumen:}

A pesar de que la ciudad de Quito fue declarada patrimonio cultural de la humanidad en 1978 por poseer uno de los centros históricos coloniales más representativos de Latinoamérica, no ha existido el interés por abordar investigaciones arqueológicas profundas. La intención de este artículo es contribuir al conocimiento de su origen colonial y prehispánico, registrado en el estudio presentado, en el que existe una estrecha relación entre el pasado precolonial y colonial. Entre los años 1988 y 1991 se llevó adelante una excavación sistemática en el convento de Santo Domingo de Quito, con el objetivo de identificar restos de su construcción original. El trabajo en el terreno posibilitó la recuperación de evidencia arquitectónica compuesta por antiguos muros y pisos asociados a cerámica precolonial y colonial. Se registraron también las primeras huellas de ocupación preinca, tanto en el ala norte como en el atrio del convento, lo que demuestra que este espacio, antes de la conquista española, estaba ocupado por un posible cementerio local tardío asociado al período de Integración entre 500 d.C. a 1500 d.C. y específicamente a la cultura Quito.

Palabras clave: arqueología histórica; Colonia; cronología; excavación; restos culturales.

\section{Abstract:}

Despite the fact that the city of Quito was declared a cultural heritage of humanity in 1978 for having one of the most representative colonial historical centers, there has been no interest in undertaking deep archaeological investigations in its historical center. The intention of this article is to contribute to the knowledge of colonial and pre-Hispanic origin registered in this study. Between 1988 and 1991, a systematic excavation was carried out in the Santo Domingo de Quito Convent, with the aim of identifying remains of its original convent construction. The work in the field made possible the recovery of architectural evidence composed of old walls and floors associated with pre-colonial and colonial ceramics. The first evidence of pre-Inca occupation was also recorded, both in the north wing and in the atrium of the convent, thus demonstrating that this space originally before the Spanish conquest was occupied by a possible late local cemetery associated with the Integration period between 500 AD. to 1500 AD associated with the Quito culture.

Keywords: historical archeology; Colony; chronology; excavation; cultural remains.

\footnotetext{
* Mag. en Antropología y Cultura, investigadora independiente y secretaria del Colegio de Arqueólogas y Arqueólogos del Ecuador. El artículo se enmarce en el Proyecto de Cooperación Técnica Ecuatoriano-Belga "La Preservación y Promoción del Patrimonio Cultural del Ecuador". Correo: vic.dominguez.sandoval@gmail.com
} 


\section{Introducción}

Los estudios sobre arqueología histórica en la ciudad de Quito se han desarrollado a partir de las intervenciones en las restauraciones arquitectónicas que se han venido efectuando en las edificaciones religiosas. Las investigaciones arqueológicas han demostrado la presencia de períodos constructivos de la ciudad colonial y de escasos hallazgos anteriores a la llegada de los españoles. Las evidencias registradas permiten comparar el dato arqueológico con el dato histórico para explicar las ocupaciones durante la colonia, cambios o modificaciones y presencia de grupos culturales propios de Quito antes de la época colonial.

La arqueología histórica llevada a cabo en el claustro principal del convento de Santo Domingo, perteneciente a la Orden de Santo Domingo, trató de definir las ocupaciones tanto de la Colonia como de la pre-Colonia. Otra de las preguntas que surgieron fue si el lado norte del claustro principal funcionaba como refectorio o comedor al inicio del convento. Para ello era necesario identificar si en este sector del claustro, donde actualmente funcionan las salas 2 y 3 del Museo Fray Pedro Bedón (compuesto de tres salas), existían evidencias de que formaba parte de un mismo ambiente separado de la sala 1.

En función de los objetivos de este estudio, las unidades de excavación ubicadas en el claustro principal se ubicaron adosadas a las paredes para poder ver sobre qué se había construido el convento y conocer los cimientos, considerando que es mucho más factible encontrar evidencias adosados a los muros que en el centro de los ambientes. De esa forma se podía conocer la relación estratigráfica entre pisos y muros.
Estas unidades fueron excavadas inicialmente por niveles arbitrarios y, una vez definidos los estratos, se procedió por niveles culturales.

\section{La arqueología histórica}

Aunque se discute muchola posición y elcampo cronológico que estudia la arqueología histórica o la arqueología llevada a cabo en centros históricos, esta puede abarcar el espacio de la prehistoria, al que se suma la información obtenida de fuentes escritas, que pueden ser primarias o secundarias, hasta épocas más recientes (Montón \& Abejez, 2015). Muchos debates se han dado sobre la discusión y la aplicabilidad de esta línea de investigación. En este trabajo se presenta una reseña de los enfoques adoptados en Latinoamérica y en Ecuador. La arqueología histórica comprende el estudio de los

\section{Aspectos materiales -en términos históricos, culturales y sociales concretos- de los efectos del mercantilismo y del capitalismo traídos de Europa a fines del siglo XV y que continúan en acción hasta hoy. Obviamente consi- derada de esta manera, la arqueología histórica abarca un campo con intereses amplios. Sin embargo, como arqueología, el foco de atención se centra en las mani- festaciones materiales del mundo, en rápida transforma- ción, después del 1500 d.C. (Orser, 2000, p. 6).}

En este contexto, este tipo de arqueología está intrínsecamente relacionada con la ocupación colonial europea del continente y surge en el siglo XX. Fue en la década de 1980 que se transformó en el campo especializado del estudio de la cultura material, momento en que los arqueólogos se interesaron por construir múltiples visiones sobre la historia reciente. Durante la década de 1990 esta 
disciplina experimentó un crecimiento rápido. Varios artículos evidencian los trabajos realizados en Sudamérica, entre los que constan las excavaciones intensivas realizadas en el casco urbano de Buenos Aires (Schávelzon, 1991); los estudios de arqueología material o arqueología histórica (Funari, 1998); la investigación exhaustiva en la colonia de Floridablanca en la Patagonia argentina, en la que se interpreta la forma del plano del poblado que determina que la Patagonia en el siglo XVIII se entiende como una sociedad patriarcal, occidental y moderna (Senatore, 2000); los trabajos en las misiones jesuitas (Zarankin, 1995), y, más recientemente, una arqueología de la dictadura y resistencia en el siglo XX (Funari \& Zarankin, 2006). Solo Brasil, Argentina y Paraguay han liderado este tipo de investigaciones que presentan historias poscoloniales sumamente relacionadas entre sí, con una fuerte conexión con Europa.

Otros estudios en conjuntos conventuales también han contribuido a conocer la fundación y el origen de las cerámicas mayólicas del conjunto eclesiástico de Santo Domingo de Lima (Iñañez \& Coello, 2012). En la conservación de ciudades, la arqueología histórica juega un papel importante, puesto que permite recuperar elementos de la cultura material, por ejemplo, documentos, arquitectura y objetos que contribuyen a definir los contextos sociales del pasado más reciente (Patiño, 2012). En Ecuador, alrededor de la década de 1980, la arqueología en centros históricos surge con el estudio de sitios relevantes relacionados con la expansión europea durante la Colonia. Las primeras investigaciones arqueológicas se inician en Quito, Cuenca y Guayaquil, en el marco de los procesos de restauración de edificaciones históricas y religiosas, con el objeto de reconstruir sus procesos constructivos, desde la apropiación del terreno hasta el estudio de colecciones cerámicas.

Con estos antecedentes, se observa que no hay mucho interés de las arqueólogas y arqueólogos ecuatorianos en el estudio de áreas históricas y que son muy pocas las investigaciones publicadas relacionadas con esos contextos. En todo caso, no ha existido continuidad en el estudio de contextos coloniales que reflejen la historia secuencial desde antes de la Colonia hasta nuestros días. Por eso los escasos aportes continúan realizándose dentro de intervenciones de restauración y rehabilitación arquitectónica de distintos espacios en los centros históricos del país.

Los trabajos en el convento de Santo Domingo (Buys \& Domínguez, 1988), el antiguo Hospital San Juan de Dios y la plaza de Santo Domingo (Rousseau, 1990) y el convento de San Francisco (Terán, 1989) proporcionaron las primeras evidencias sobre los períodos prehispánico y colonial en el centro histórico de Quito. Los estudios arqueológicos tuvieron como objetivo develar la información necesaria para solucionar la problemática de la restauración arquitectónica de los principales conventos y monasterios de la ciudad, a fin de entender cómo a través del tiempo estos espacios habían sido construidos, modificados y restaurados. Además, se analizó el contexto de ocupaciones anteriores a estas construcciones coloniales y cómo, desde una perspectiva colonial, estas se convertían en elementos de poder y simbiosis social y religiosa.

Desde este enfoque, no solamente se trata de restaurar lo visible sino de tener un testimonio de las edificaciones coloniales y poner al descubierto esos símbolos que contribuyen al conocimiento 
del pasado. Es así como en 1985 se iniciaron los primeros estudios de arqueología histórica en el convento de San Francisco de Quito, donde se registraron evidencias de cimientos precoloniales y entierros coloniales que fueron asociados al siglo XVI. Estos cimientos, hechos de canto rodado y argamasa de arcilla conocida como pirca, fueron atribuidos a la ocupación prehispánica del lugar (Terán, 1989).

En 1987, en el marco del proyecto de cooperación técnica Ecuador-Bélgica, denominado ECUABEL, entre el Instituto Nacional de Patrimonio Cultural y la Cooperación Técnica para el Desarrollo de Bélgica, se iniciaron los trabajos de restauración en el convento de Santo Domingo, que fue fundado por los dominicos en 1534. Se planteó un estudio integral que incluía pintura mural, pintura de caballete, restauración arquitectónica, análisis ambiental, urbano, histórico y arqueológico. En vista de que la construcción en su conjunto se encontraba en mal estado de conservación, se debía no solamente analizar la estructura edificada, sino entenderla como la mixtificación de las huellas dejadas a través del tiempo, como reconstrucciones, modificaciones, ampliaciones, etc. De esta forma se convertía en un documento histórico de primer orden acerca del proceso de implantación colonial sobre un sistema cultural preexistente, que hay que saber transcribir y entender como repositorio histórico que guarda las huellas de las ocupaciones anteriores a la Colonia, que quedaron bajo los cimientos de paredes, pisos y modificaciones de la que fue objeto el edificio a través de los años de su construcción.

Se realizó la restauración del convento con base en la estrategia de intervención de todos sus componentes arriba mencionados y con ella se llevó a cabo una investigación arqueológica.
Posteriormente, se hicieron los análisis de los archivos de la biblioteca y los libros de cuentas de la comunidad dominica. Todo este conjunto de estudios realizados por las distintas áreas del proyecto permitió llevar a cabo una reconstrucción de los eventos culturales partiendo desde los siglos XV y XVI (Terán, 1994), cuando se inició su construcción, hasta la década de 1980. El objetivo era conocer la historia constructiva a través de la identificación de las sucesivas fases de edificación para establecer una cronología relativa de las modificaciones arquitectónicas de este y de las ocupaciones predecesoras.

Entre 1989 y 1990 se llevaron a cabo trabajos de restauración arquitectónica en el antiguo Hospital San Juan de Dios y en la plaza de Santo Domingo de Quito. Para ambos lugares, la investigación arqueológica estaba contemplada dentro del marco de este tipo de intervenciones. En el caso del Hospital San Juan de Dios, se registró la evidencia de restos de edificios incas en la iglesia, asociados a recipientes de cerámica de la misma filiación, como la presencia de un aríbalo, pero por falta de conocimiento de esta época en Quito se asumió como resultado hipotético. Además de encontrar cimientos de origen colonial que demuestran la continuidad de las ocupaciones en el área y de evidencias de la construcción de la iglesia a principios del siglo XVII, se hallaron canales de piedra y ladrillos, independientes de la estructura de la iglesia, que probablemente correspondían a una estructura anterior asociada a la casa de Pedro de Ruanes o a transformaciones que se dieron a finales del siglo XVI. Los datos demostraron que durante el siglo XVIII el subsuelo fue utilizado como un cementerio que podría ser de la Orden de los Betlemitas (Rousseau, 1990). 
En la plaza de Santo Domingo de Quito se registraron evidencias de restos cerámicos, metal oxidado, restos óseos faunísticos y canales de ladrillo que atraviesan este lugar de oeste a este, siguiendo la pendiente del terreno (Rousseau, 1990). Alrededor de la misma época también se hicieron otros trabajos puntuales en la iglesia El Robo del convento de Santa Clara, donde se definió la presencia de entierros coloniales. Asimismo, en el convento de San Agustín, los datos mostraron evidencias de la presencia de urnas coloniales.

Estos estudios han dado como resultado un conjunto de información acerca de estructuras y objetos muebles relacionados con distintos aspectos de la vida quiteña religiosa durante las épocas prehispánica, colonial y republicana, desde los tempranos tiempos de la fundación de la ciudad hasta inicios del siglo XX. Investigaciones en el atrio de San Francisco que registraron la presencia de basureros asociados a vasijas de filiación tardía o definida como Quito y entierros coloniales (Domínguez, 1998a); evidencias encontradas en el atrio de la Catedral de los cambios en el tipo de escalera de bramante, varios sistemas de canales y entierros, asociados a la época colonial (Domínguez, 1998b), y un posible muro de filiación Inca registrado en la casa del Cadisán (Delgado \& Bravo, 2002), entre otros, han contribuido con información sobre este período de ocupación en el centro histórico de Quito.

En esta época se desarrollaron también algunos estudios en otras ciudades de Ecuador. Entre 1991 y 2001, en el centro histórico de Guayaquil se llevaron a cabo intervenciones arqueológicas previas a la realización de túneles en la ciudad, trabajo que fue realizado por el Instituto Nacional de Patrimonio Cultural, Subdirec- ción Regional del Litoral. En esta investigación se efectuó un trabajo exhaustivo sobre el análisis de las mayólicas del Guayaquil temprano (15411690), en el que se concluyó que la cerámica registrada era de origen panameño; es decir, que la vajilla de esta época era preferentemente importada (Chancay, 2007).

En Cuenca, se realizó un trabajo acerca de la arquitectura y el material cultural del período colonial en esta ciudad, donde se efectuaron excavaciones en dos casas rurales y dos casas urbanas, lo que permitió clasificar tanto material cultural inca y colonial como republicano, cuya cultura material es considerada como visible, pero con significados particulares (Jamieson, 2003). En este caso, se definieron claramente diferencias en el uso del utillaje de la élite cuencana. A través de la cultura material evidente en las casas de Cuenca queda patente la marcada segregación existente en el siglo XVII. Además, se hizo un análisis completo de la cerámica colonial y republicana (ibíd.). Esta investigación significó un esfuerzo pionero porque antes no se había desarrollado un trabajo completo que abarcara varios ejemplos en esta ciudad.

\section{Metodología}

En el caso del convento de Santo Domingo, el estudio se centró en la definición de las ocupaciones preexistentes basadas en la información estratigráfica y documental de los distintos pisos o contextos definidos, subyacentes a muros, y la materialidad tanto prehispánica como hispánica, esta última asociada al siglo XVI. El conjunto conventual de Santo Domingo fue objeto de un estudio integral de recuperación del patrimonio cultural. En el marco del Proyecto ECUABEL, 
se emprendieron tareas de restauración del bien inmueble y de los bienes muebles.

En este contexto se planificaron tres fases de excavaciones en la Capilla de Santa Rosa de los Naturales, en los corredores occidental y noreste del claustro principal, en el Museo Fray Pedro Bedón y en la plaza de Santo Domingo. En estos espacios o áreas del convento se excavaron 13 unidades y 2 trincheras en el Museo Fray Pedro Bedón, 6 unidades y 1 trinchera en la Capilla de Santa Rosa de los Naturales, 9 en el corredor oeste, 7 en el corredor este y 4 en el jardín del claustro principal, 6 en el corredor norte y 1 en la plaza de Santo Domingo (Tabla 1).

Tabla 1. Dimensión y profundidad de las unidades excavadas

\begin{tabular}{|c|c|c|c|}
\hline Sector & Unidad & Superficie en m & Profundidad en m \\
\hline \multirow{7}{*}{$\begin{array}{l}\text { Corredor oriental } \\
\text { y carpintería del } \\
\text { claustro principal }\end{array}$} & $\mathrm{A} 1$ & $1,30 \times 3,50$ & 3,17 \\
\hline & $\mathrm{A} 2$ & $1,25 \times 3,55$ & 3,35 \\
\hline & A3 & $1,50 \times 2,00$ & 2,90 \\
\hline & A4 & $1,00 \times 3.00$ & 3,01 \\
\hline & $\mathrm{A} 6$ & $1,20 \times 1,50$ & 1,55 \\
\hline & A7 & $2,00 \times 8,00$ & 2,38 \\
\hline & A8 & $1,92 \times 1,85$ & 1,30 \\
\hline \multirow{9}{*}{$\begin{array}{l}\text { Corredor } \\
\text { occidental }\end{array}$} & U9 & $3,00 \times 3,75$ & 2,49 \\
\hline & U10 & $3,50 \times 2,00$ & 2,82 \\
\hline & U11 & $3,00 \times 2,00$ & 0,80 \\
\hline & U12 & $1,40 \times 3,00$ & 1,21 \\
\hline & U13 & Columna & ochavada \\
\hline & U14 & $7,60 \times 1,70$ & 1,61 \\
\hline & U15 & $2,50 \times 2,00$ & $0,51 \mathrm{~cm}$ a 1,35 \\
\hline & U17 & Columna & ochavada \\
\hline & U18 & $1,20 \times 0,80$ & 1,21 \\
\hline \multirow{6}{*}{ Corredor norte } & E5 & $1,00 \times 1,50$ & 2,90 \\
\hline & C12 & $3,70 \times 3,00$ & 1,83 \\
\hline & C15 & $2,00 \times 2,00$ & 3,70 \\
\hline & C16 & $1,80 \times 2,00$ & 1,35 \\
\hline & $\mathrm{C} 17$ & $2,00 \times 1,20$ & 3,70 \\
\hline & C19 & $2,00 \times 1,50$ & 1,35 \\
\hline
\end{tabular}




\begin{tabular}{|c|c|c|c|}
\hline Sector & Unidad & Superficie en $\mathrm{m}$ & Profundidad en $\mathrm{m}$ \\
\hline \multirow{4}{*}{$\begin{array}{l}\text { Jardín del } \\
\text { claustro principal }\end{array}$} & E1 & $1,00 \times 0,60$ & 0,80 \\
\hline & E2 & $1,70 \times 1,10$ & 1,48 \\
\hline & E3 & $1,70 \times 1,00$ & 1,20 \\
\hline & E4 & $2,00 \times 1,30$ & 1,48 \\
\hline \multirow{15}{*}{$\begin{array}{l}\text { Museo Fray } \\
\text { Pedro Bedón }\end{array}$} & C1 & $0,95 \times 1,95$ & 3,15 \\
\hline & $\mathrm{C} 2$ & $1,74 \times 0,87$ & 3,12 \\
\hline & C3 & $1,50 \times 0,90$ & 0,85 \\
\hline & $\mathrm{C} 4$ & $1,00 \times 1,50$ & 0,94 \\
\hline & $\mathrm{C} 5$ & $1,00 \times 1,50$ & 0,94 \\
\hline & C6 & $1,00 \times 0,85$ & 0,85 \\
\hline & Trinchera 1 & $1,00 \times 4,50$ & 0,94 \\
\hline & $\mathrm{C7}$ & $1,00 \times 4,10$ & 0,94 \\
\hline & $\mathrm{C} 8$ & $3,93 \times 2,00$ & 1,88 \\
\hline & $\mathrm{C} 10$ & $2,72 \times 1,20$ & 1,25 \\
\hline & C11 & $2,00 \times 2,60$ & 2,93 \\
\hline & $\mathrm{C} 13$ & $2,38 \times 1,00$ & 1,70 \\
\hline & C14 & $1,50 \times 1,00$ & 1,53 \\
\hline & Trinchera 2 & $7,72 \times 1,00$ & 0,60 \\
\hline & C18 & $1,00 \times 1,50$ & 1,66 \\
\hline \multirow{2}{*}{ Atrio } & Entierro 22 & $1,00 \times 0,50$ & 2,00 \\
\hline & Entierro 23 & $1,00 \times 0,51$ & 2,00 \\
\hline \multirow{7}{*}{ Capilla Santa Rosa } & Trinchera A & $18,00 \times 1,00$ & 0,44 \\
\hline & U1 & $2,00 \times 1,30$ & 1,90 \\
\hline & $\mathrm{U} 2$ & $2,00 \times 1,20$ & 1,49 \\
\hline & U3 & $3,60 \times 1,50$ & 2,59 \\
\hline & U4 & $1,20 \times 1,40$ & 1,43 \\
\hline & U5 & $1,75 \times 1,00$ & 5,00 \\
\hline & U6 & $2,64 \times 1,05$ & 0,57 \\
\hline
\end{tabular}

Una vez que el equipo de arquitectos del área de restauración realizó los levantamientos del espacio y del piso actual para su conservación, el área quedó liberada para la colocación de las unidades antes indicadas y orientadas con relación a los ejes arquitectónicos del convento.
Es decir, la mayoría de las unidades fueron adosadas a las paredes para poder definir mejor los cimientos de la misma. Las dimensiones de las unidades variaron de acuerdo con el espacio dispuesto en los distintos ambientes, pero generalmente eran más las trazadas de un 
metro cuadrado y de cuatro metros cuadrados o con trincheras de un metro de ancho, o dependiendo de los espacios en los corredores, mismas que se definieron con base en los siguientes criterios:

- De acuerdo con el objetivo central, que era entender la estratigrafía cultural de cada sector del convento.

- De acuerdo con el avance de los trabajos del área de arquitectura.

- De acuerdo con las interrogantes que debían ser resueltas para el área de arquitectura del convenio.

Este tipo de estudio recibe un enorme aporte que comprende la investigación histórica hecha por especialistas y que se realizó en los archivos del convento y demás fondos que fueron necesarios revisar para poder entender el proceso constructivo. El aporte de la historia sirvió para contestar todas las preguntas que encierra esta forma de estructuras coloniales.

En este trabajo se incluyen los resultados de las fechas radiocarbónicas realizadas por el Instituto Real de Patrimonio Artístico (IRPA) de Bélgica y del análisis de los huesos humanos efectuados por el doctor Douglas Ubelaker (Ubelaker, 1991). También incluye una columna estratigráfica de las ocupaciones. Los rellenos y pisos levantados fueron excavados de manera sistemática para entender el proceso ocupacional del convento.

Para conocer el conjunto cerámico es necesario hacer un análisis que permita entender el proceso de producción alfarero observado en el tiempo, a través del estudio de atributos de las dimensiones de pasta, acabado de superficie, decoración y definición de formas.

\section{El convento eclesiástico de Santo Domingo}

El conjunto conventual de Santo Domingo es una de las edificaciones religiosas más antiguas que forma parte del tejido urbano del centro histórico de Quito. Se asienta en una manzana con una extensión de dos hectáreas entre las calles Flores, Rocafuerte, Montufar y Pereira, en el sector conocido como la Mama Cuchara. El conjunto está compuesto por el claustro principal, el claustro secundario, el claustro del coristado, la iglesia, el presbiterio y el antiguo colegio San Luis Beltrán, hoy en día colegio San Fernando (Figuras 1 y 2). 
Figura 1. Ubicación del convento de Santo Domingo de Quito

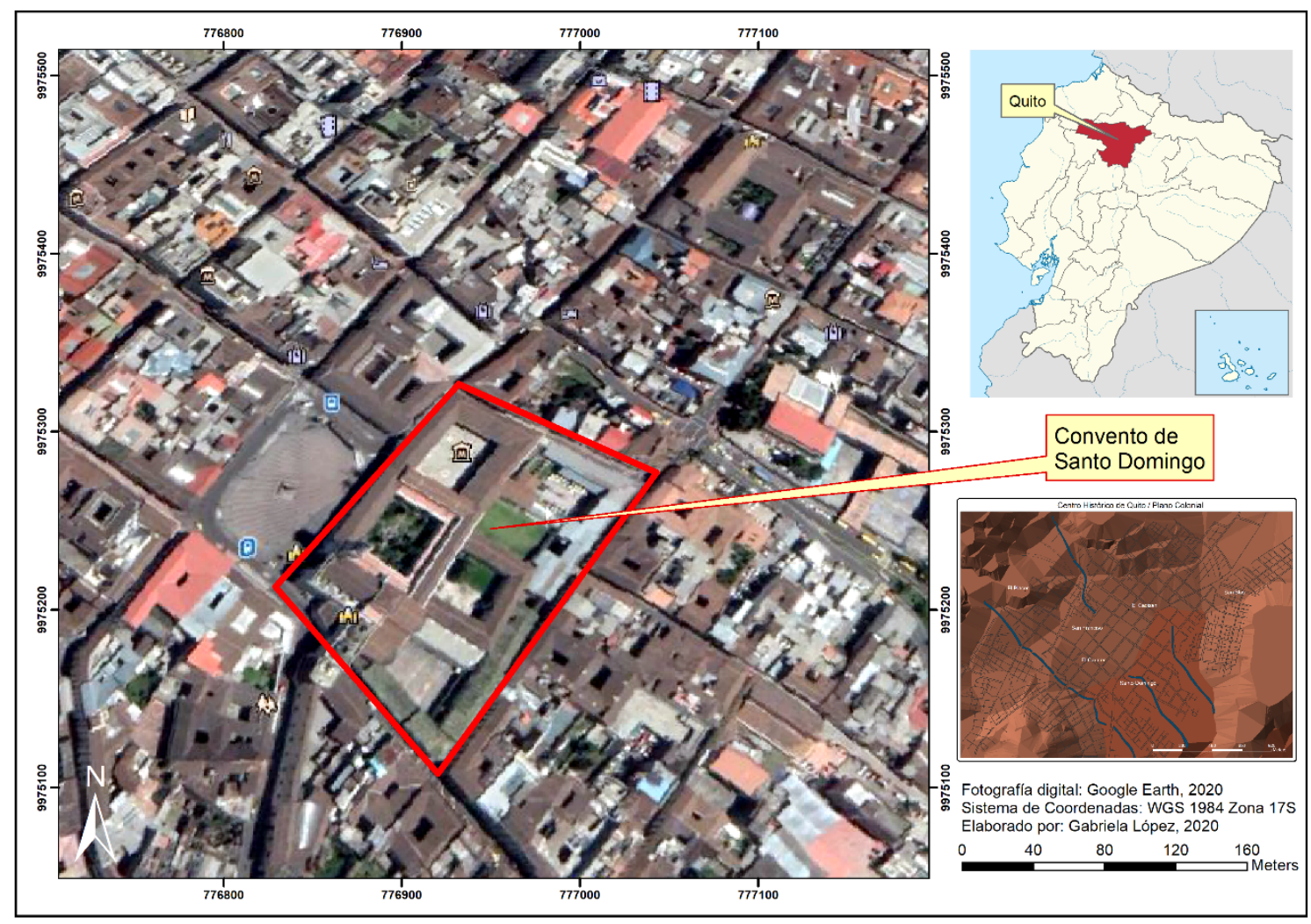

Elaborado por Gabriela López.

Figuras 2a) Vista general del convento. 2b) Fachada principal y atrio del convento

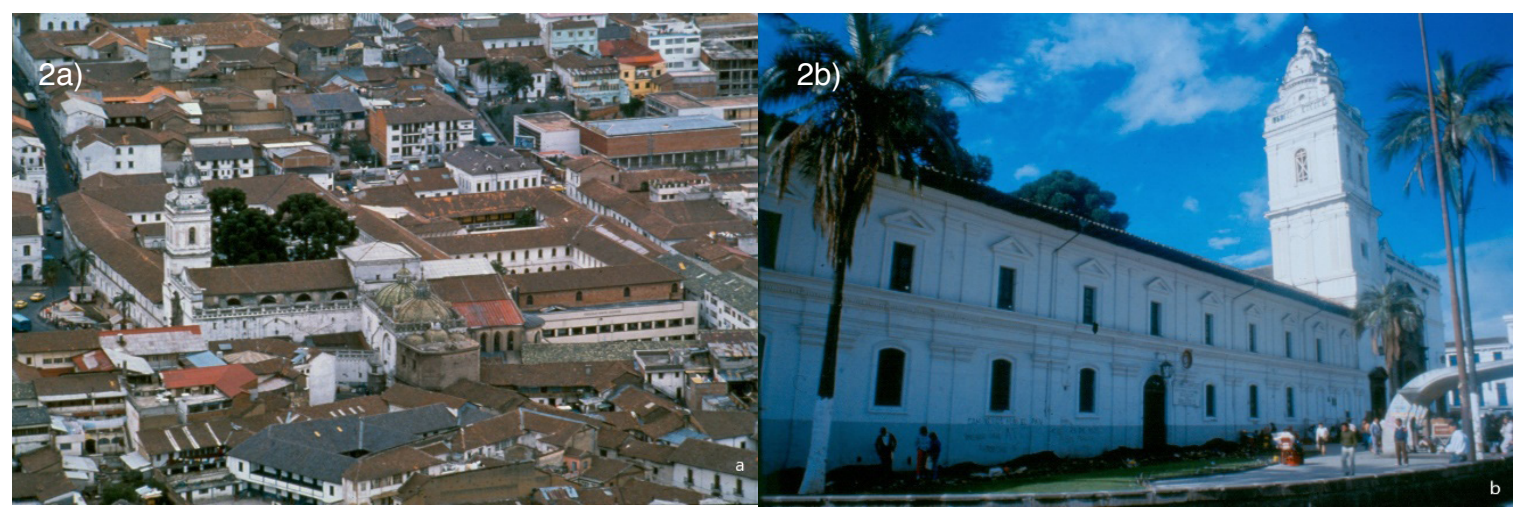

Fuente propia. 
La Orden de los Dominicos se estableció en Quito alrededor de 1541, fecha en la que los solares para instaurar el convento fueron solicitados al Cabildo de la ciudad por fray Gregorio Zarazo (Terán, 1994). Los terrenos requeridos por la orden dominica estaban ubicados en el extremo oriente de la recién instalada ciudad de San Francisco de Quito, flanqueados por dos grandes quebradas. La primera, ubicada al lado sur, conocida originalmente como Ullaguanguayacu, tomó posteriormente el nombre de quebrada de Jerusalén y luego de 24 de mayo, hoy es el bulevar del 24 de mayo; y la segunda, llamada quebrada de Manosalvas, bajo la actual calle Pereira, ubicada en el área conocida como La Loma, está completamente aislada del núcleo urbano que se estaba instalando durante la colonia. De acuerdo con Terán (1994), en la loma de Santo Domingo existía un antiguo asentamiento de yanaconas, registrados en un padrón de indígenas de San Sebastián que data de 1582 (Salomon, 1980) y que resaltaba la presencia de indios panaderos del convento que vivían a sus espaldas (Terán, ibíd.).

Según Terán (1994) existieron dos etapas constructivas, la primera es del inicio del otorgamiento hasta 1560-1570. Entre 1561-1565, bajo la responsabilidad del padre fray Jerónimo de Cervantes, se cercó la propiedad y se inició la construcción del claustro principal (Vargas 1967, p. 49, citado en Buys \& Domínguez, 1988). Con estas obras arranca la segunda etapa, que se extiende hasta 1620, año de inicio de la construcción del convento actual, sin incluir el templo (Terán, ibíd.). En el siglo XVII (1650), la iglesia fue terminada en su construcción principal. La falta de asignaciones para la construcción de un gran claustro ocasionó que su primera construcción fuera "muy humilde", tal como lo menciona Pedro de Aguayo en 1573 (Vargas, 1967).
En 1581 llega a Quito el renombrado arquitecto español Francisco Becerra, a quien le solicitan que elabore los planos del convento, pero parece que no construyó más allá de los cimientos. La iglesia era una sola nave con grandes hornacinas (Vargas, 1986). Finalmente fue el padre Rodrigo de Lara Manrique quien, a partir de 1595, llevó a cabo la verdadera edificación y la concluyó a mediados del siglo XVII (Vargas, 1967).

En el análisis del proceso constructivo, el único dato registrado es el revisado por Terán: una relación de Rodríguez Docampo de 1650, que comprende una probanza que emite el convento entre 1604-1607 para que se le otorgue limosna de vino, aceite, etc., y que añade una asignación de indígenas para la edificación de este (Terán, 1994).

En 1650 se termina el claustro principal, donde intervino el franciscano fray Antonio Rodríguez. En el siglo XVII se construyen la iglesia, las capillas y se coloca la cruz de piedra en el centro de la plaza. Entre 1700 y 1770 se consolida el convento con la construcción, tal como es en la actualidad, del segundo claustro o colegio de San Fernando.

Alrededor de la misma fecha, el refectorio antiguo o comedor conventual debe haber cambiado de función, lo que quizá se asocie a la fecha de 1760 (Buys, Camino, Santamaría \& Zambrano, 1994). En el siglo XVIII se construyó el arco de Santo Domingo y ya para el siglo XIX, toman auge en el sector las casas y la plaza (Terán, 1994).

En 1868, el terremoto de lbarra destruyó la cúpula y el campanario de la iglesia. Luego, en 1883, la restauración de los padres italianos abrió naves laterales. A finales del siglo XIX, los dominicos remodelaron la iglesia, ampliándola con un coro bajo y una capilla (Alemán \& Van Balen, 1994). 
Como vemos, debido a los costos que representaba llevar una obra de gran envergadura para esa época, no fue posible construir el conjunto en una sola vez; por el contrario, la demora de los recursos ocasionó que esta obra se diera por terminada luego de tres siglos.

En 1988, en el marco del Proyecto ECUABEL "Preservación y Promoción del Patrimonio Cultural del Ecuador", se elaboró un convenio bilateral cuyo objetivo era capacitar a personal ecuatoriano del Instituto Nacional de Patrimonio Cultural. Este fue firmado en septiembre de 1987 y dentro de él se escogió al convento de Santo Domingo como centro de todas las actividades relacionadas con la salvaguardia, restauración y promoción del patrimonio cultural. Estas comprendieron: inventario cultural del área, restauración, conservación, museología, museografía, catalogación del archivo, conservación de bienes muebles, arqueología y su correspondiente puesta en valor, es decir, inter- pretarlo, recuperarlo, protegerlo y difundirlo para fortalecer la identidad de los pueblos.

Así se inició la investigación arqueológica en el Museo Fray Pedro Bedón como un estudio previo a la restauración del monumento. El objetivo principal era conocer la secuencia cronológica y determinar los cambios y las funciones del claustro principal.

\section{La ocupación prehispánica en el claustro principal}

Los trabajos de excavación en las tres áreas del convento (claustro principal, Museo Fray Pedro Bedón y atrio del convento) dieron como resultado evidencias relacionadas con la ocupación prehispánica local, las primeras construcciones coloniales y su consolidación como estructura conventual (Figura 3).

Figura 3. Ubicación de unidades y hallazgos arqueológicos en el claustro principal y del atrio del convento de Santo Domingo.

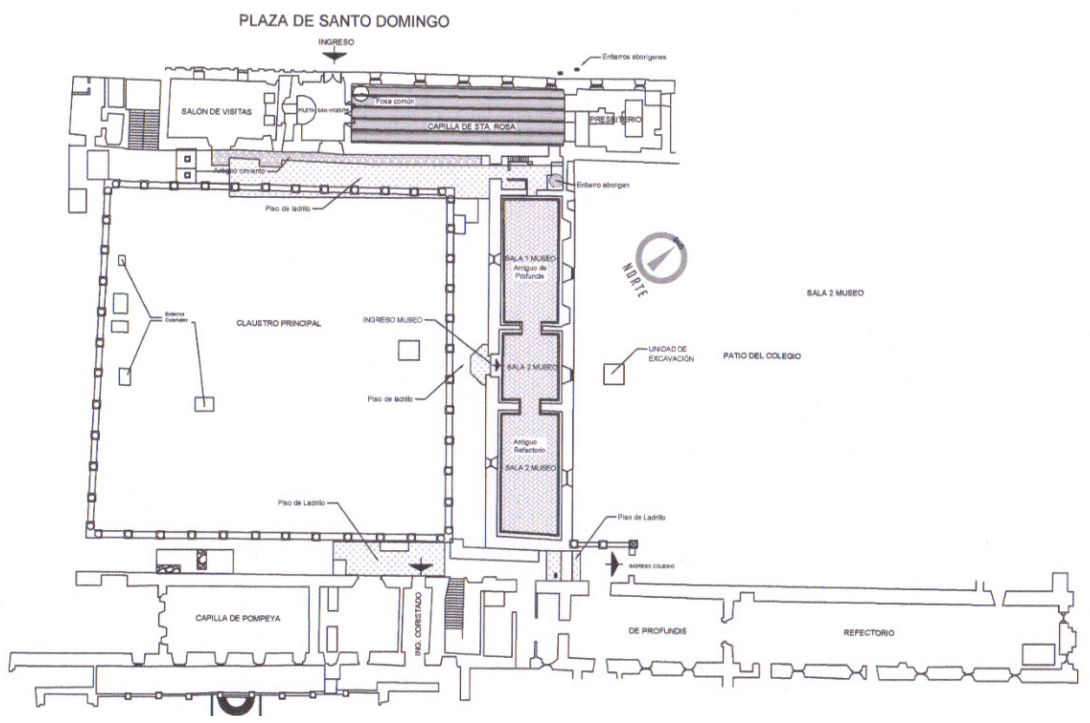

Elaborado por Gonzalo Gordon. 
Además de establecer la secuencia constructiva del convento y sus modificaciones espaciales a través de los años, se identificaron elementos anteriores a la conformación conventual, asociados exclusivamente a contextos funerarios. Estos edificios, obviamente de gran significación cultural, llevaron a las costumbres hispanas de la época a instalar las iglesias sobre espacios simbólicamente significativos para la comunidad local, como prueba de un proceso de colonización que estaba empeñado en borrar las huellas y costumbres paganas desde una mirada del colonialismo clásico de la época para emprender un proceso evangelizador de imposición. Evidencias de este tipo de construcciones también pueden ser encontradas en la Catedral Metropolitana de México, que fue construida sobre la pirámide del Sol de los aztecas.

Varias tumbas de la ocupación tardía de Quito, asociadas a ajuares funerarios y de contexto secundario, fueron registradas in situ, con una distribución espacial desligada de la configuración conventual actual. La primera se registró en la sacristía de la Capilla de Santa Rosa, la segunda fue una fosa común en el lado suroeste de la nave de la misma capilla y la tercera comprendió el hallazgo de dos tumbas en la plaza de Santo Domingo frente a la fachada del claustro principal del convento. Es probable que aún existan más enterramientos, tanto en el convento como cerca de la fachada principal, en el atrio de la plaza.

\section{Capilla de Santa Rosa de los Naturales}

En la sacristía se registró la presencia de un entierro (E2R2) de contexto secundario debajo de un piso de ladrillo, a una profundidad de 88 $\mathrm{cm}$ y asentado sobre la cangagua ${ }^{1}$ estéril. Este individuo estaba conformado por un cráneo y varios huesos largos, asociado a cuatro ganchos de propulsor, cinco pulidores, dos flautas de hueso, dos fragmentos de hacha, dos narigueras de cobre, una argollita y diente de herbívoro, colocados alrededor del cráneo, además de una vasija fragmentada con engobe rojo en el exterior entrecruzado. Aunque esta evidencia no fue perturbada por los cimientos de la construcción final, sin embargo, se observan varios hoyos de poste que pueden estar asociados a la construcción inicial del convento (Figura 4). Este tipo de ajuar funerario podría asociarse directamente con actividades de caza.

Figuras 4a) Entierro secundario prehispánico local. 4b) Planta del entierro secundario prehispánico. 4c) Ajuar funerario: herramientas en piedra, ornamentos en cobre. 4d) Jarro con pintura entrecruzada en el cuerpo.
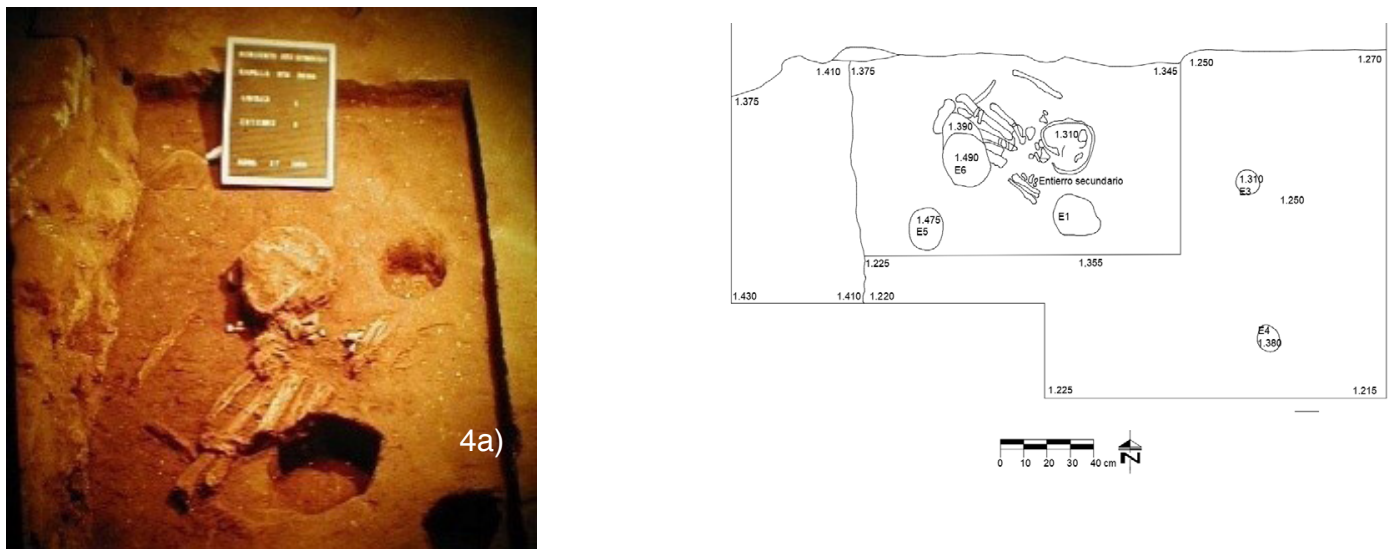

4b) 

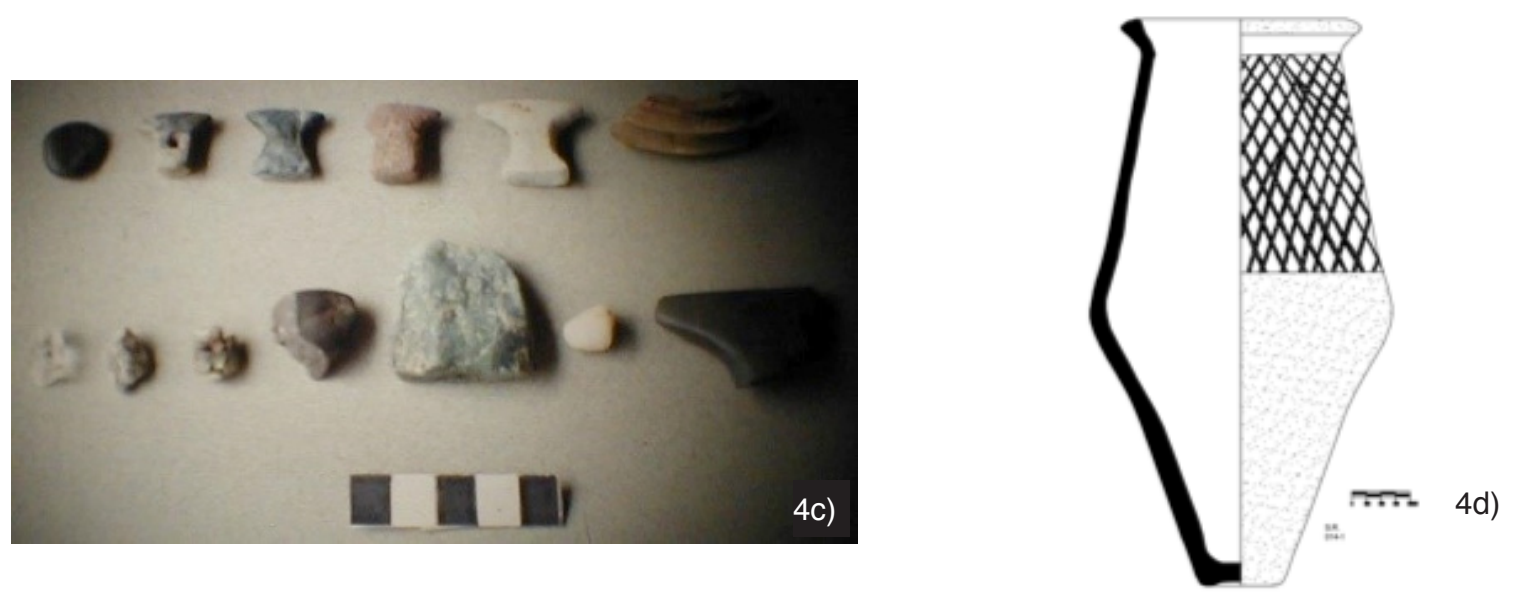

Fuente propia.

En la nave de la capilla de Santa Rosa o de los Naturales, específicamente en el muro suroccidental del claustro principal, se definió la presencia de una fosa común que aparece a una profundidad de $1,80 \mathrm{~m}$ y que fue excavada por niveles o capas de huesos, y que tiene un alto de 1,52 m. Está compuesta por 500 huesos humanos asociados a 39 individuos, 29 adultos y 10 individuos prematuros. También mostraron enfermedades de infección, anemias, tumores y enfermedades dentarias. Igualmente, el hallazgo de esta fosa común se encontraba desligada de la configuración estructural del convento; probablemente ocurrió al momento de construir los cimientos del claustro principal, lo que ocasionó el reacomodo de las tumbas en un lugar específico de la pequeña iglesia. Los estudios de antropología física realizados en los restos óseos y el desgaste de los dientes suponen una fuerte asociación con una filiación temprana, cuyas fechas radiocarbónicas dieron 1523, 1564 y 1629 d.C. (IRPA/1092), asociadas al primer momento de contacto con los españoles (Ubelaker, 1991) (Figura 5).

Figura 5. Fosa común y corte sección
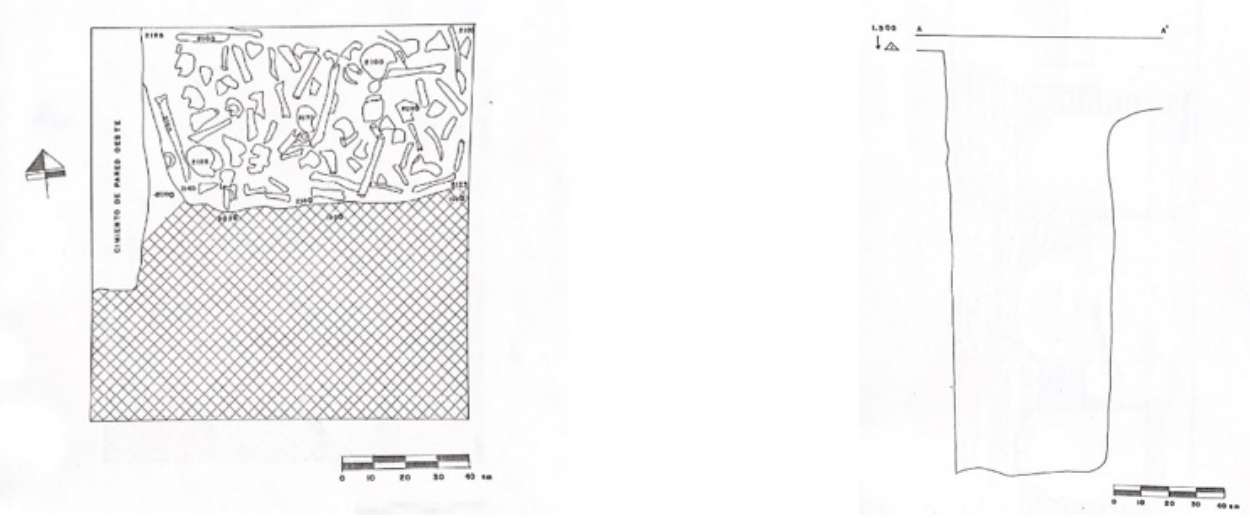

Elaborado por Gonzalo Gordon. 
En el caso de la fosa común, aunque estos huesos pertenecen probablemente al Periodo Colonial Temprano, representan posiblemente a la población indígena del primer momento. A manera de hipótesis, la reubicación de los entierros en la fosa en los primeros años de la conquista fue realizada al momento en que el ala occidental del convento se convierte en Capilla de los Naturales, lo que debe haber ocurrido alrededor del siglo XVI o a principios del siglo XVII.

\section{Plaza de Santo Domingo}

Las otras dos evidencias de los entierros se registraron en la plaza de Santo Domingo y comprendieron dos entierros secundarios en el exterior del convento, sin evidencia de fosa alguna. Durante la excavación realizada por el municipio de Quito para arreglar tuberías de agua en el área antes mencionada, se encontraron dos entierros.
El entierro E22R22 aparece a 3.00 metros al oeste de la pared frontal del convento y a una altura de 1.870 metros en un relleno de textura suave de color , se encuentra en mal estado de conservación debido al alto grado de humedad. Se trata de un entierro secundario que presentó el cráneo con sus extremidades superiores e inferiores completas y ciertas vertebras. Su ajuar funerario se compone de una compotera (cuenco con base) de cuerpo esferoidal con labio recto y pedestal (Figura 6a). En cambio, el entierro E23R23 se ubica $2 \mathrm{~m}$ al norte del entierro mencionado y comprende un entierro incompleto en posición semiflexado, compuesto por extremidades superiores e inferiores, pero en mal estado de conservación, debido al alto grado de humedad. El ajuar funerario de este entierro era de una sola olla rota in situ, de cuello restringido, cuerpo esférico y base anular (Figura 6b).

Figuras 6a) Recipiente: compotera. 6b) Olla de base anular de la tumba E22R22.
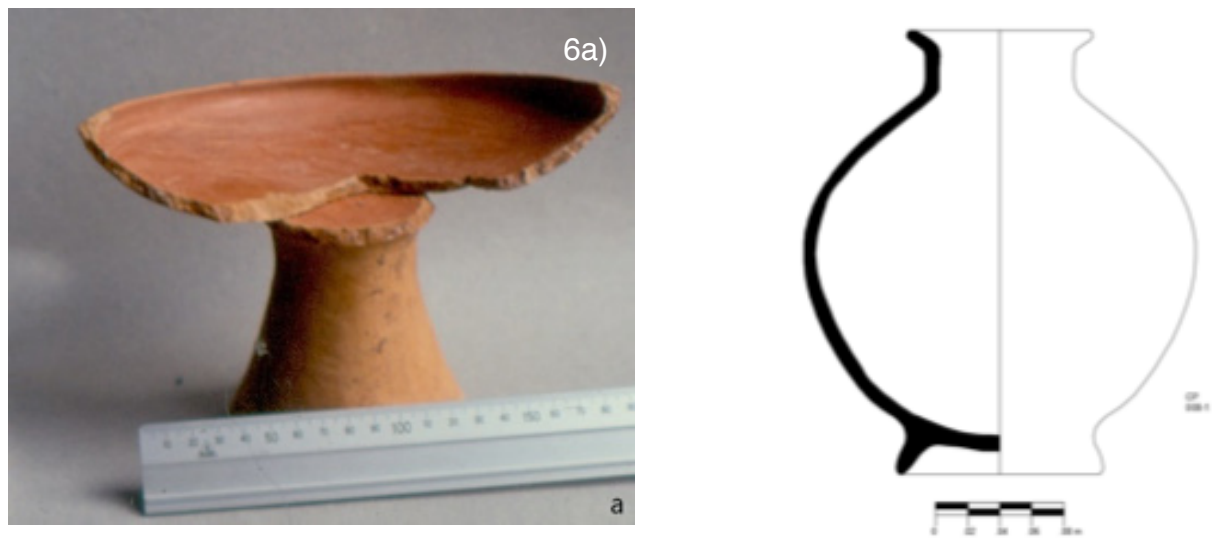

6b)

Fuente propia. 
Estos vestigios funerarios permiten inferir que la zona estuvo ocupada probablemente por un cementerio o asociada tal vez a otras funciones. Estos datos se relacionan con la ocupación Quito del área de estudio.

\section{La ocupación colonial del convento de Santo Domingo}

Por encima de las evidencias anteriormente mencionadas se van a observar, en el claustro principal del convento, una serie de elementos constructivos que van desde la época de la Colonia hasta casi la actualidad.
Museo Fray Pedro Bedón

y corredor norte del claustro principal

El Museo Fray Pedro Bedón se ubica en el ala norte del claustro principal del convento. Está compuesto por tres salas, con un único acceso que se localiza en la mitad de su pared sur. Mide $34,20 \mathrm{~m}$ de largo y un ancho que varía de 6, 50 $\mathrm{m}$ a $6,63 \mathrm{~m}$, con paredes de $1,10 \mathrm{~m}$ de espesor (Figuras 2 y $7 a$ y b).

Figuras 7a) Fachada del Museo Fray Pedro Bedón. 7b) Jardín del claustro principal.
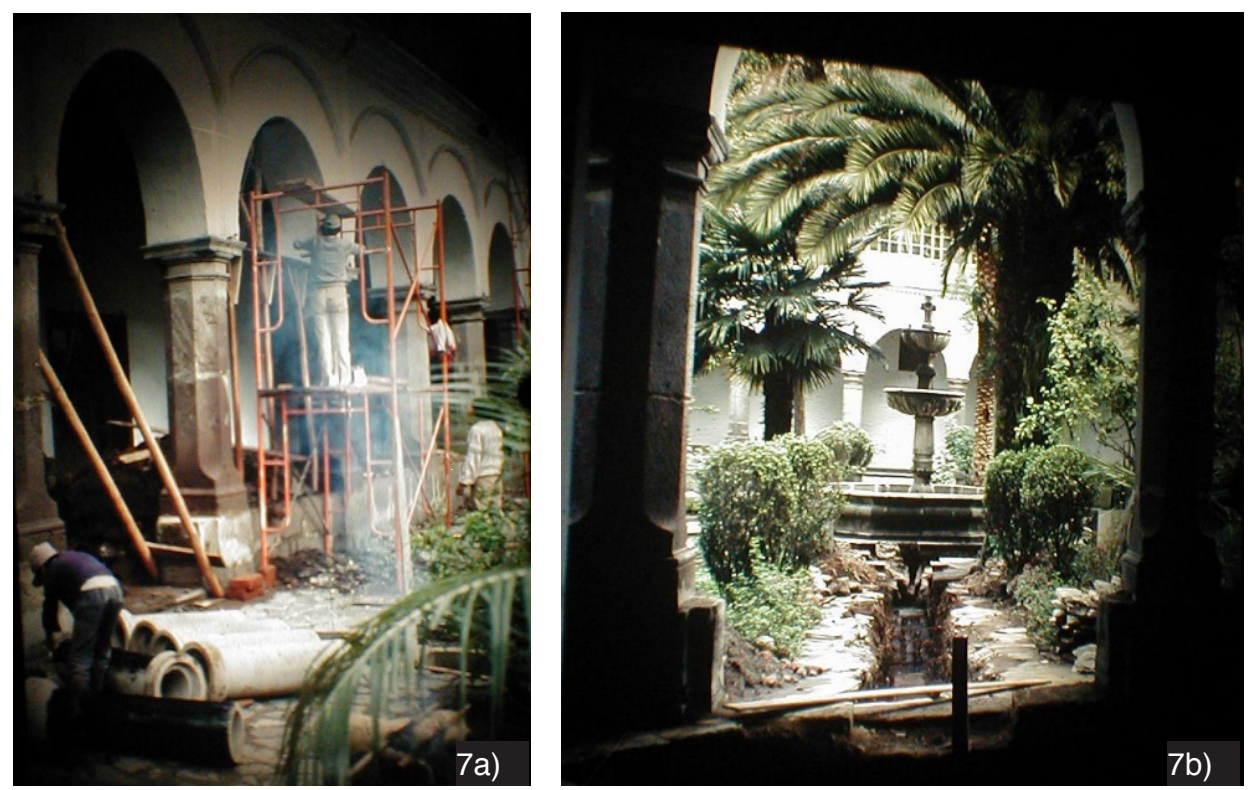

Fuente propia.

En el museo, las excavaciones indicaron que los cimientos del convento fueron construidos a $3 \mathrm{~m}$ de profundidad con una construcción sólida de tipo arriscado; es decir, se combi- naron piedras grandes con piedras o cuñas pequeñas, aunque en otras áreas del museo se observó más mortero de cal y arena que piedras (Figura 8). 
Figura 8. Cimiento de pared del conjunto conventual.

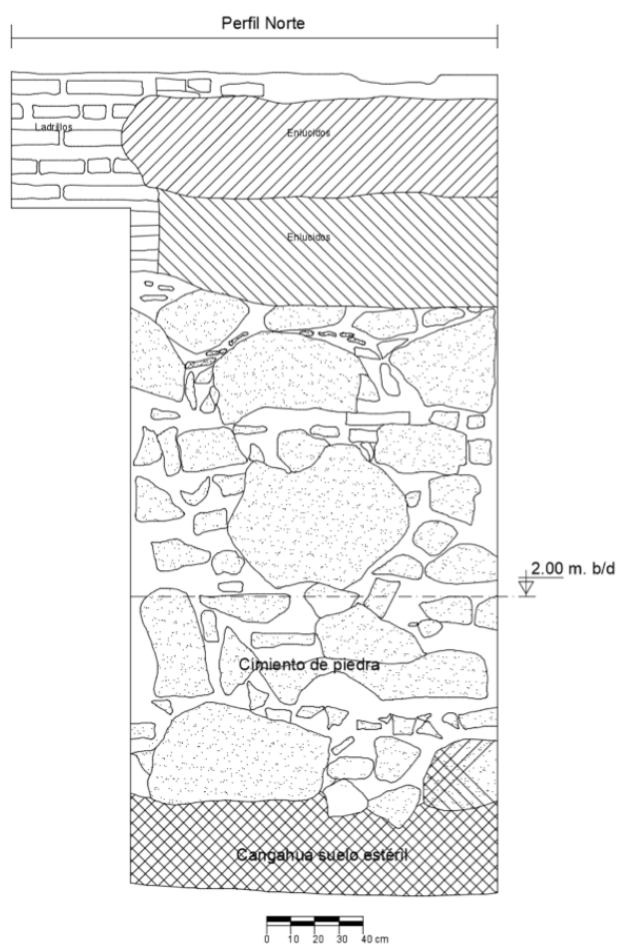

Elaborado por Gonzalo Gordon.

En el interior del edificio, encima de la cangagua (toba volcánica fina) o estrato natural, se definió la presencia de una superficie de uso, de tierra apisonada, que debió haber sido la superficie de trabajo a la hora de la construcción del museo, donde también se encontraron hoyos de poste, así como abundante cerámica y restos óseos faunísticos, además de elementos constructivos que debieron obedecer al momento de la construcción inicial del convento o por lo menos de esta ala del claustro principal. Esta superficie estaría asociada a la segunda mitad del siglo XVI y al primer decenio del siglo XVII. En el ala occidental y el extremo oeste del museo, estas evidencias fueron destruidas por completo por la construcción de un sistema de bóvedas existente en el área.
A esto se suma la presencia de un piso de ladrillo con diseño "espina de pez", que fue definido en los corredores occidental y oriental del claustro principal, en las dos salas del actual Museo Fray Pedro Bedón y en la sacristía de la Capilla Santa Rosa de los Naturales a una profundidad de 1,00 $\mathrm{m}$ bajo el nivel del actual piso de piedra. Al lado suroeste, el piso de ladrillo está asociado a un muro de adobe enlucido sobre una base de piedra que se proyecta hacia el jardín. En este mismo lado, se definieron la presencia de dos columnas ochavadas independientes de las actuales columnas del claustro. Las dos salas del museo, por las evidencias de unos bancos circundantes, debieron ser parte del antiguo refectorio y de profundis considerado como una antigua sala de los edificios conventuales, donde se celebraban asambleas de los religiosos, o como antesala 
del comedor desde 1610 hasta 1688, cuando tada probablemente a mediados del siglo XVI. se construyó el actual refectorio (Buys \& Domín- Frente a la entrada principal de este se encontró guez, 1988). Estos elementos son prueba de una un piso semihexagonal con un canal abierto en primera construcción conventual completamente su alrededor. Su presencia estaría indicando el desplazada de la configuración actual, levan- centro del claustro principal inicial (Tabla 2).

Tabla 2. Secuencia estratigráfica del convento de Santo Domingo de Quito (Buys y Domínguez, 1988).

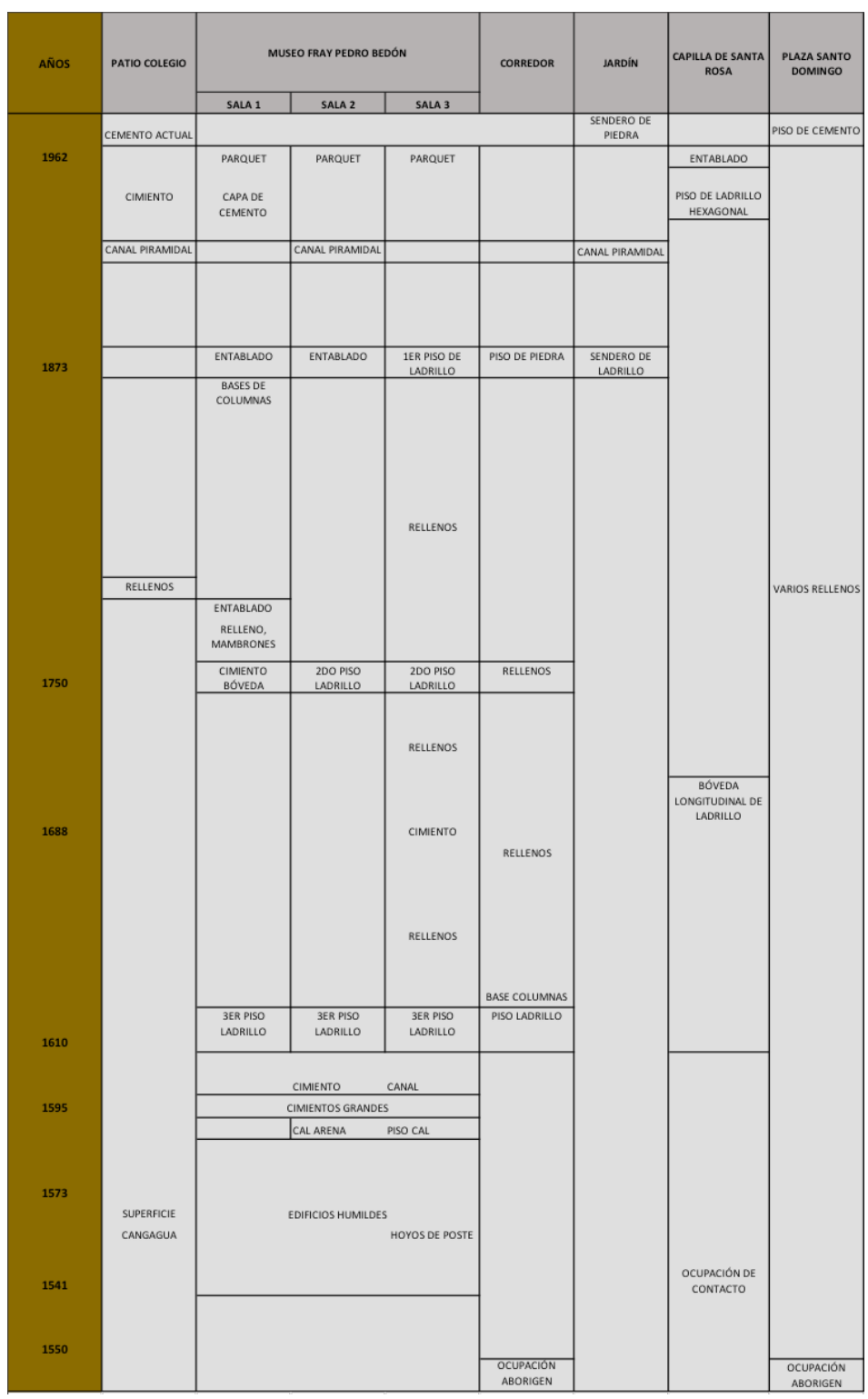

Nota: Modificado por la autora. 


\section{Evidencias acerca del convento grande}

El aumento de monjes de la orden dominica ocasionó la necesidad de hacer un nuevo convento, mismo que se llevó a cabo en el siglo XVII. Los planos hechos por el arquitecto Francisco Becerra contemplaron el diseño de dos claustros ubicados "a caballo" (entiéndase este término como proceso de traslapar una construcción encima de otra) sobre el convento inicial o de fundación. Se hicieron cimientos grandes y se elevó la construcción en sus paños. La evidencia queda en el Museo Fray Pedro Bedón, bajo la forma de la superficie de uso debajo del tercer piso de ladrillo, donde se aprecian hoyos de postes grandes y pequeños que probablemente sirvieron para colocar los palos de andamios, así como restos de los materiales de construcción (Figura 9).

Figura 9. Estratigrafía del convento.

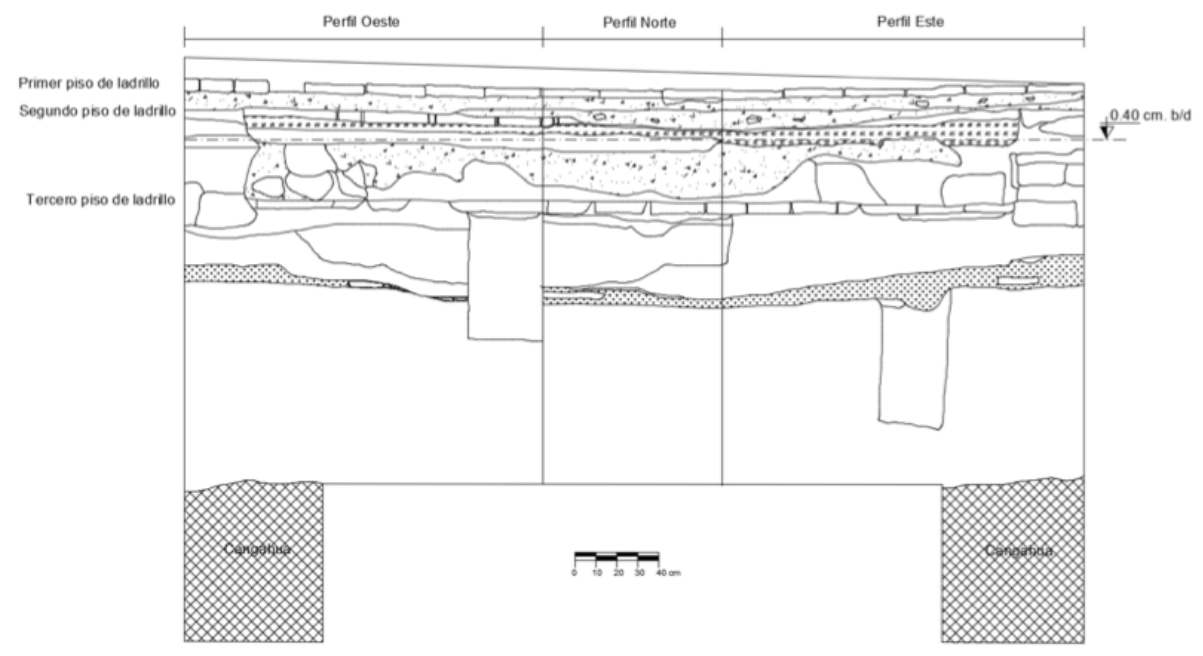

El tercer piso asentado sobre mortero de cal y arena fue encontrado en las tres salas del museo a una profundidad de entre 84 y 88 $\mathrm{cm}$. Este piso estaba compuesto de ladrillos rectangulares de color 5YR 4/6 yellowish red, de $31 \times 18 \mathrm{~cm}$, con un espesor de entre 4 y 5 $\mathrm{cm}$, y unidos con mortero de cal y arena, en un diseño "espina de pez", rodeado por una orla que bordea toda la sala. Asociado a este piso se registró la presencia de un banco de $45 \mathrm{~cm}$ de alto, el cual estaba compuesto de adobes y tierra compactada, con fragmentos de ladrillo, y que en la cara que da hacia la sala se encuentra cubierto por un enlucido hecho de cal y arena. Se hallaba bordeando todas las paredes de las dos salas y también en el umbral de la puerta de entrada. Se observan además otras modificaciones en cambios de paredes y aberturas de puertas, etc. (Figuras 9 y 10a-b). 
Figuras 10a) Tercer piso de ladrillo (siglo XVII). 10b) Detalle del piso y banco de ladrillo.

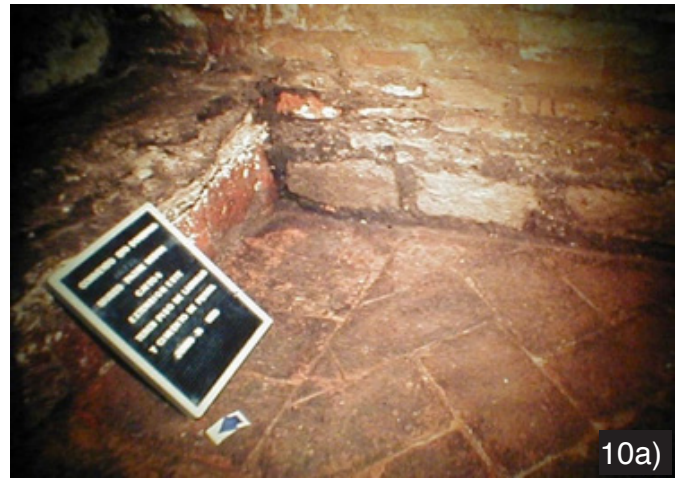

Fuente propia.

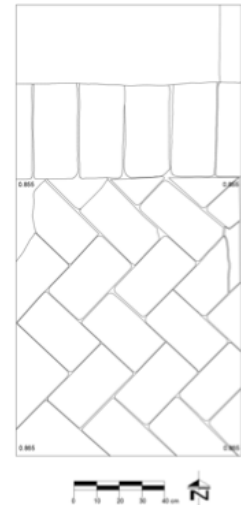

10b)
En esos tiempos, las salas 2 y 3 del museo eran parte del antiguo refectorio, que comprendió una sala grande con un banco alrededor para que se sentaran los monjes. Esto explicaría también la presencia de varios hoyos, que constituirían los lugares donde se asentaron las mesas. De acuerdo con Vargas (1986), para 1611 pudo haber en el convento aproximadamente 70 religiosos. En cambio, la sala 1, por sus características, debió haber servido como el de profundis. La ubicación del antiguo comedor en el ala norte del claustro refleja la costumbre religiosa de ubicarlo en el ala opuesta a la iglesia (Vargas, 1986). Para la mitad del siglo XVII, el segundo claustro estaba en construcción y el actual refectorio debió haber sido terminado en 1688 y, como consecuencia de ello, esta sala debió haber cambiado de función. En el siglo XVIII se colocaron rellenos encima para subir el nivel, cuando se colocó el segundo piso de ladrillo.

El segundo piso de ladrillo de las salas 2 y 3 del museo se registró a una profundidad de entre 42 y $46 \mathrm{~cm}$. En él se continuó con la tradición del diseño "espina de pez", rodeado por una orla, pero con ladrillos rectangulares de $42 \times 21 \mathrm{~cm}$, con un espesor de entre 4 y $5 \mathrm{~cm}$, de color marrón fuerte 7.5YR 4/6 strong brown, más grandes que el piso anterior y asentados sobre un mortero de cal y arena. El hallazgo de un sello de plomo, asociado a una modificación posterior a la presencia de este piso, podría remontar su construcción a la segunda mitad del siglo XVIII, ya que el sello parece datar de la primera mitad del siglo XIX.

Además de anotar en la sala 1, que el hallazgo de las bóvedas de ladrillo con mortero de chocoto que quedan justo debajo del piso de madera, podrían ser cámaras de aire para la ventilación interna de esta parte del edificio o también pudo haber combinado con una función estructural relacionada con la cercanía de las quebradas para ganar más superficie a la pendiente inclinada de esta parte de la ciudad. Se postula que el refectorio antiguo dejó de funcionar entre finales del siglo XVII y principios del siglo XVIII, cuando se colocó este segundo piso de ladrillo. De acuerdo con Kennedy (1989), el siglo XVIII fue un período de reparaciones y adecuaciones en la edificación y no de grandes construcciones. 
El soporte del segundo piso estaba compuesto de diferentes capas de rellenos con fragmentos de adobes y ladrillos, y a veces adobes completos. Después del segundo piso de ladrillo en la sala 2 , se colocó el canal piramidal a juzgar por la trinchera que corta el piso. Este canal conecta la pileta central del claustro principal con el patio del actual colegio San Fernando y de ahí se dirige hacia la quebrada, que quedó abierta, quizá porque este espacio dejó de funcionar. Esto podría datar de la segunda mitad del siglo XIX.

Entre el primer y tercer piso, se observaron varias bóvedas de ladrillos unidas con mortero de chocoto. Su forma se asocia a un sistema de ventilación. Sin embargo, su presencia no se justifica en asociación con estos elementos culturales.

El piso más reciente o primer piso de ladrillo de la sala 3 y las bases y piedras piñones de la sala 1 corresponden a una fase construc- tiva posterior. De acuerdo con una comunicación personal del padre Luis Tipán, ex prior del convento, hasta 1932 las salas 1 y 2 tenían un piso de madera con columnas para sostener el tumbado y un muro las separaba de la sala 3 , donde funcionaba una carpintería, dato que coincide fácilmente con el registro arqueológico. Este primer piso, compuesto de ladrillos cuadrados de $29 \times 30 \mathrm{~cm}$, de color amarillo rojizo $7.5 Y R$ 5/8 reddish yellow, con un espesor de $5 \mathrm{~cm}$, sin mortero, sobre bases de relleno compactado, encima del cual colocaron tierra suelta para asentar el piso localizado en la sala 3, estaba debajo del parquet. Aparece a una profundidad de $31 \mathrm{~cm}$ bajo la superficie de madera actual. Este testimonio permite postular que este piso probablemente fue construido en la segunda mitad o a fines del siglo XIX (Figura 11). En 1962 el ala norte del claustro se convirtió en museo y se colocó el parquet procedente de la iglesia. 
Figura 11. Primer piso de ladrillos cuadrados.

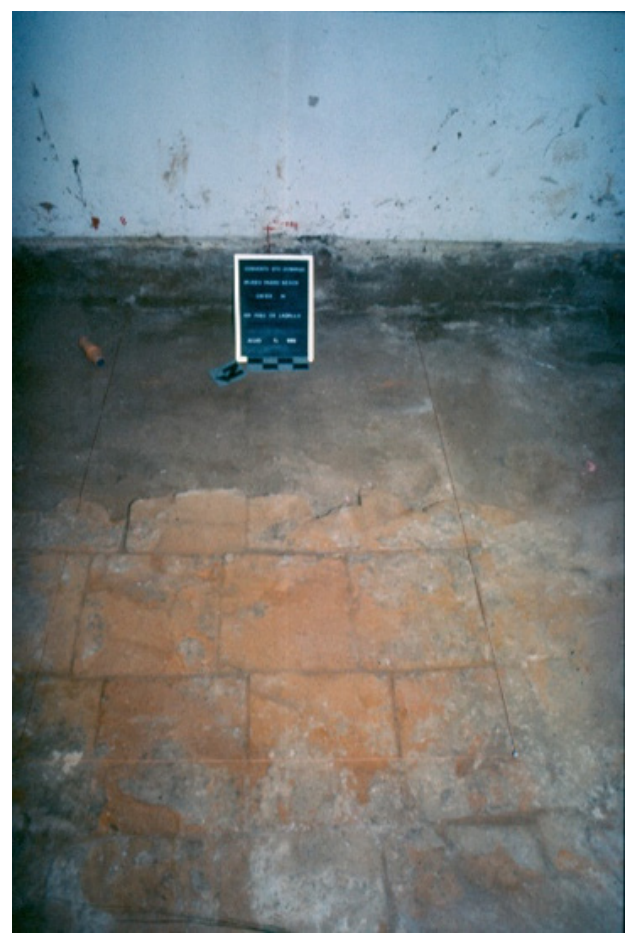

Fuente propia.

Capilla de Santa Rosa de los Naturales

La Capilla de Santa Rosa se ubica en el ala noroeste del claustro principal, mide $36 \mathrm{~m}$ de largo x $6 \mathrm{~m}$ de ancho. Ahí se excavaron varias unidades y una trinchera tanto en la nave como en el presbiterio. La superficie actual comprende un entablado de madera, debajo del cual se encontró un piso de ladrillos hexagonales (Figuras 12a y b).

Figuras 12a) Vista general de la capilla. 12b) Muestras de los ladrillos hexagonales.
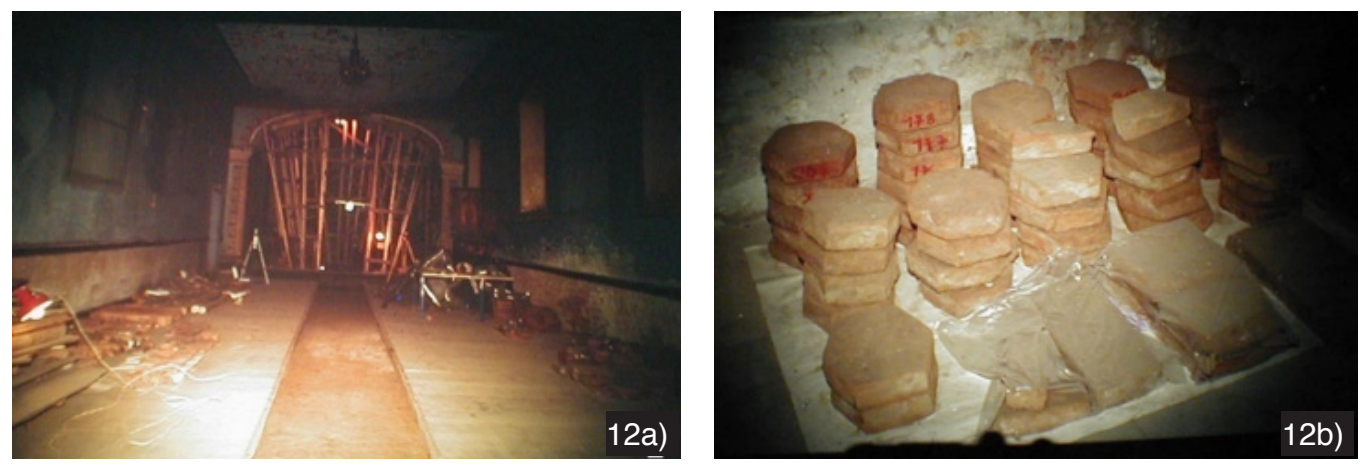

Fuente propia. 
En el presbiterio de la Capilla Santa Rosa de los Naturales se observan dos marcos de piedra que corresponden al ingreso de una cripta. En la grada que separa la nave del presbiterio, se registró la presencia de una tapa rectangular grande que forma el ingreso a la cripta. Esta está construida por ladrillos unidos con mortero de cal y arena, y ocupa casi todo el espacio del presbiterio. Su techo está elaborado a manera de una bóveda que abarca casi todo este espacio. En la parte sur de la cripta se encuentran varios nichos a lo largo de las paredes. En el nicho del lado este se halló un esqueleto adulto de aproximadamente $1.68 \mathrm{~m}$ de alto, cuya edad estimada es de entre 45 y 60 años, junto a restos de textil y sandalias (Ubelaker, 1991).
En la nave de la capilla, debajo del piso hexagonal y de unos cuantos rellenos, se encontraron 5 bóvedas paralelas al eje de la nave. Los ladrillos de las bóvedas están unidos con mortero de chocoto y comparten muros laterales. Cada 2 metros están interconectadas mediante una apertura lateral. Su cúspide aparece a $36 \mathrm{~cm}$ debajo del entablado actual. El interior de las bóvedas mide $78 \mathrm{~cm}$ de alto $\times 80 \mathrm{~cm}$ de ancho y estas se asientan sobre la cangagua. Al final de la bóveda cerrada existe una pequeña apertura, igual que en las laterales. En el sur estas están cortadas por la pared divisoria entre la Capilla Santa Rosa de los Naturales y la Capilla San Vicente; al norte están cerradas por un pequeño muro de ladrillo (Figura 13a-b).

Figuras 13a) Bóvedas de ladrillo de la capilla Santa Rosa.

13b) Detalle o corte sección de las bóvedas.
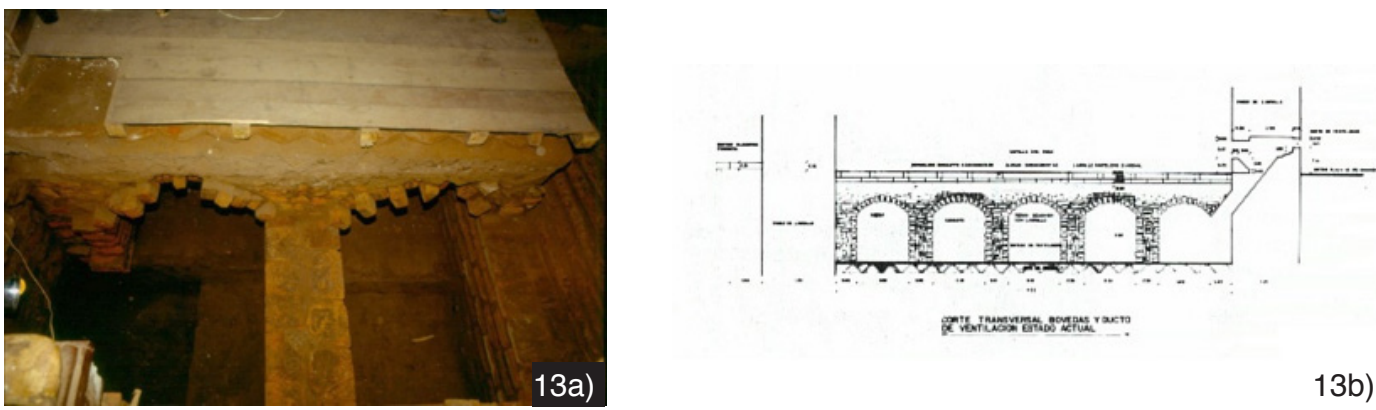

Fuente propia.

\section{Material cultural}

Con relación al material cultural del convento, se ha podido registrar tanto la presencia de cerámica prehispánica como colonial. Ambas proceden principalmente de los rellenos registrados en las distintas unidades del conjunto conventual. Se registró la presencia de 4.718 fragmentos, entre mayólicas $^{2}$ y terracota ${ }^{3}$, y 6.238 restos óseos faunísticos. Se encontraron escasos restos de metal, lítica, vidrio y concha. La cerámica colonial procede principalmente de los rellenos entre el segundo y tercer piso de ladrillo, debajo del piso de piedra del corredor. En cambio, la cerámica prehispánica se halló asociada al banco del tercer piso de ladrillo y al cuarto piso del museo (Figura. 14). 
Figura 14. Tipos de cerámica.

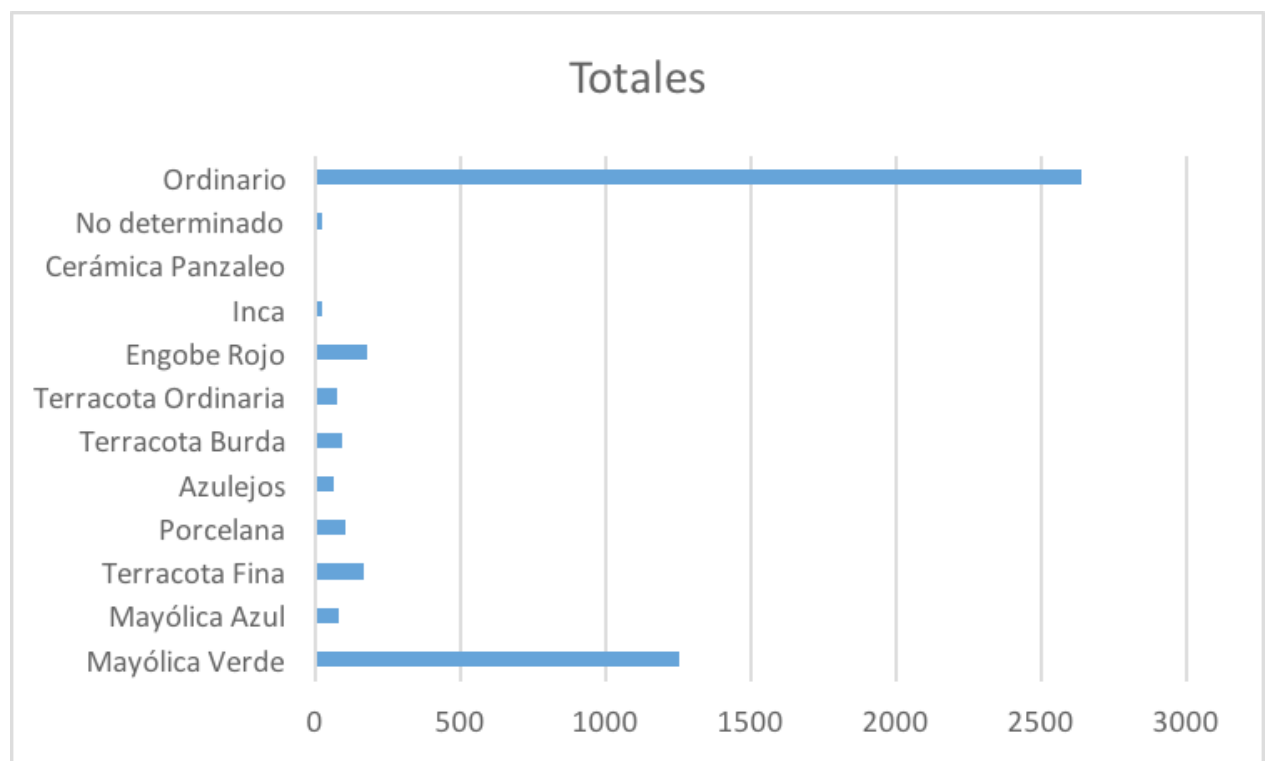

Del material obtenido podemos destacar, en primer lugar, la cerámica tanto colonial como republicana, la cual es la más representativa y ha servido para obtener información sobre los motivos decorativos y diversas formas utilizadas, sean escudillas, cuencos, tazas, copas y demás menaje de casa. No queremos entrar en detalles sobre los estilos ceramográficos coloniales, pues creemos que aún no tenemos una secuencia maestra que nos sirva de guía para clasificar a la cerámica ecuatoriana de los siglos XVI, XVII y XVIII. El conjunto cerámico fue clasificado de manera más fácil, pero claramente definido y caracterizado como cerámica colonial, cerámica republicana y cerámica prehispánica.

La cerámica colonial presenta una pasta bien cocida de color amarillo rojiza $5 Y R$ 6/8 reddish yellow con desgrasante fino, con un espesor de las paredes que oscila entre 4 y $13 \mathrm{~mm}$.
Muestra engobe blanco verdoso vidriado $5 Y R$ 7/2 light gray, decoración zonal de color verde esmeralda, azul y marrón. Se ha podido definir la presencia de platos hondos, cuencos, una olla, asas de jarras y una base de un posible cuenco. Entre los otros restos, se ha registrado la presencia de fragmentos de baldosas, un tubo de canal, etc.

Los platos hondos son de borde evertido y cuerpo hemisférico con base anular. La variabilidad la reflejan en la decoración: presentan línea en el borde, algunos del tipo vidriado y es frecuente ver elementos florales donde se combinan el verde esmeralda con el color café. Algunos ejemplos de las bases presentaron diseños de tréboles en cruz con líneas cortas intermedias, con un motivo que se asemeja a flores de Lis, uno de los emblemas religiosos de la orden dominicana que representa la pureza (Figuras 14 y 16). 
Figuras 15a y 15b) Ejemplos de platos. 15c) Ejemplo de una jarra.
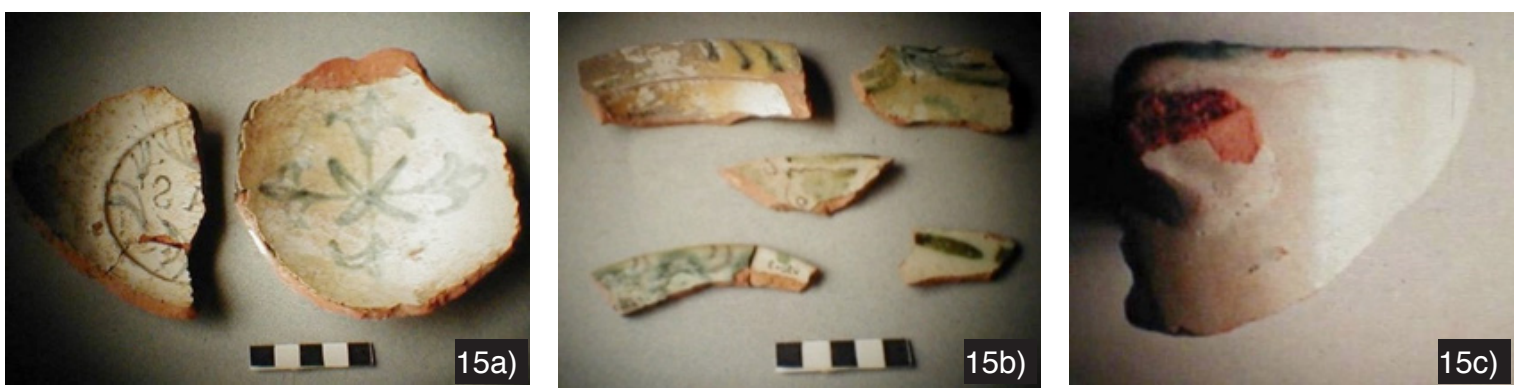

Fuente propia.

Figura 16. Categorías de vasijas coloniales.

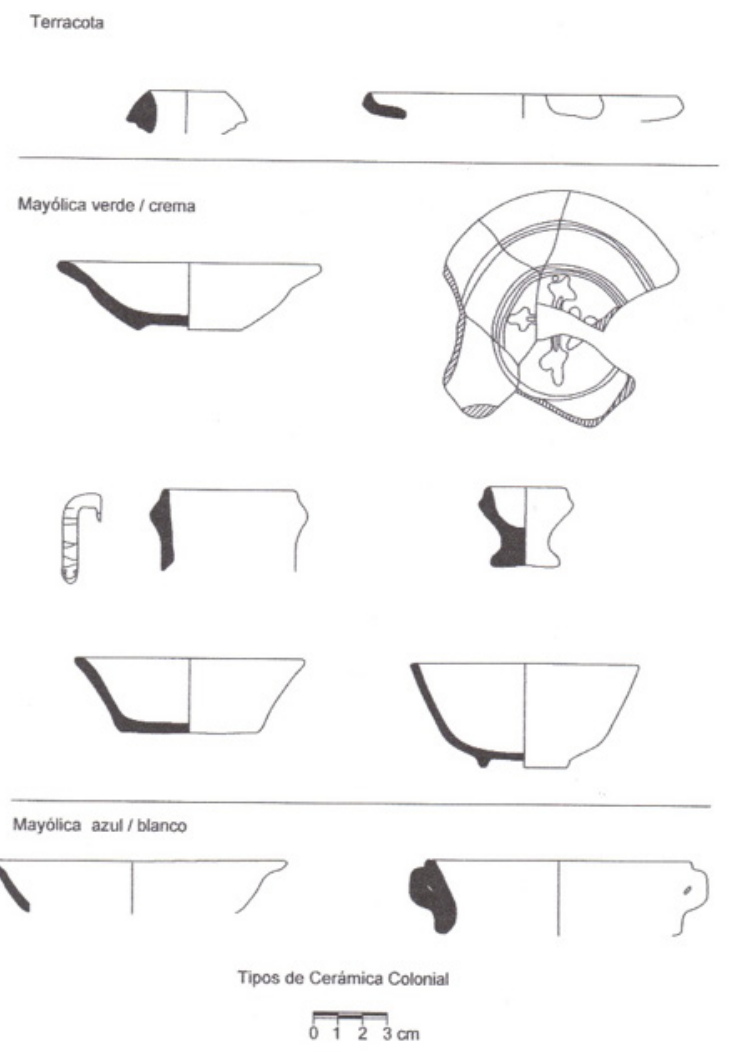

Elaborado por Gonzalo Gordon. 
Algunos de los cuencos de bordes directos de cuerpo hemisférico tienen una línea verde en el labio; el resto presenta vidriado en ambas caras de la superficie. Otro cuenco tiene borde horizontal con vidriado verde en el interior y apenas alisado al exterior. Hay un solo ejemplo de una olla de borde evertido y verde vidriado en ambas caras del recipiente. Las asas son evidencia de la existencia de jarras, con vidriado blanco y líneas gruesas de color verde esmeralda.
Es interesante resaltar la presencia de baldosas con un espesor que va entre 15 y 25 $\mathrm{mm}$, con las características de manufactura que la cerámica. Un solo ejemplo presentó un lado completo que midió $18 \mathrm{~cm}$; tal vez sean cuadradas o rectangulares, y es común ver la combinación de colores entre líneas verde esmeralda y celeste, y más delgadas de color café, de posible diseño floral (Figura 17).

Figura 17. Fragmentos de baldosas con diseños de colores en verdes y cafés.

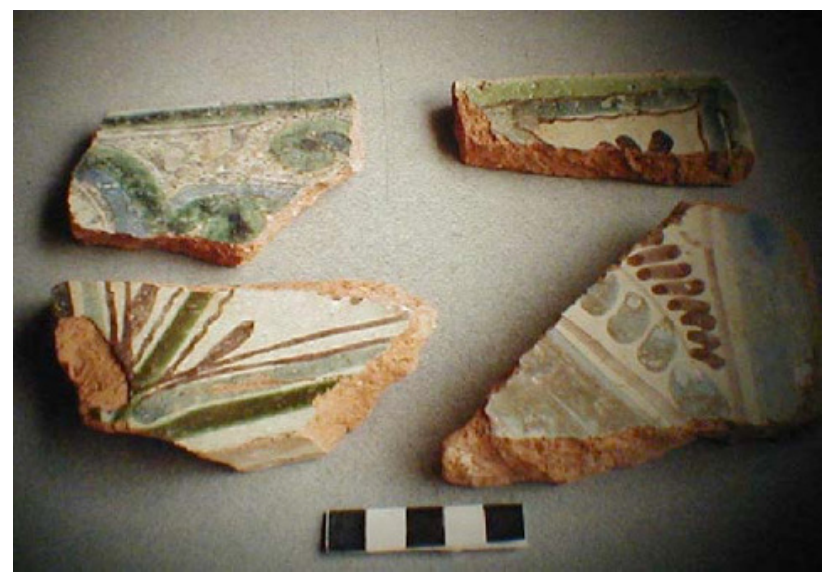

Fuente propia.

El segundo grupo grande comprende una cerámica de origen prehispánico, aunque en algunos casos podrían ser de manufactura española con modelos antiguos. Durante la Colonia perduró la utilización de formas precolombinas en los acabados y la decoración. Algunos objetos tenían una función utilitaria o doméstica y otros son de una categoría más fina. Presentan acabados alisados, algunos tienen engobe rojo en el interior, que es lo más frecuente. El utillaje también se compone de cuencos y ollas. Está también presente un borde horizontal de recipiente pequeño, de paredes muy finas, con decoración exterior en líneas entrecruzadas de color rojo, de filiación Cosanga o cerámica de origen amazónico que está presente en sitios de la Sierra Ecuatoriana como parte de ajuares en tumbas o en contextos domésticos, preferentemente en las ocupaciones tardías (Figura 18a).

Con relación a la cerámica fina, esta muestra un engobe rojo pulido de buena calidad (Figura 18b), a los que se suman un fragmento de tortero con acabado de superficie de engobe rojo en el interior y alisado en el exterior (Figura 18c). Cinco fragmentos son de filiación Inca con 
decoración en diferentes colores: negro, rojo y blanco, a manera de rombos, y un damero en rojo sobre blanco. Su procedencia de los rellenos más antiguos indica probablemente que en el área también hay huellas de la ocupación Inca sin contexto definido (Figura 18d-f), además de los ajuares cerámicos propios de la ocupación tardía o Quito (Figura 18g-i).

Figuras 18a) Cerámica de filiación Cosanga. 18b y 18c) Cerámica de filiación Quito. 18d, 18f) Cerámica de filiación Inca.

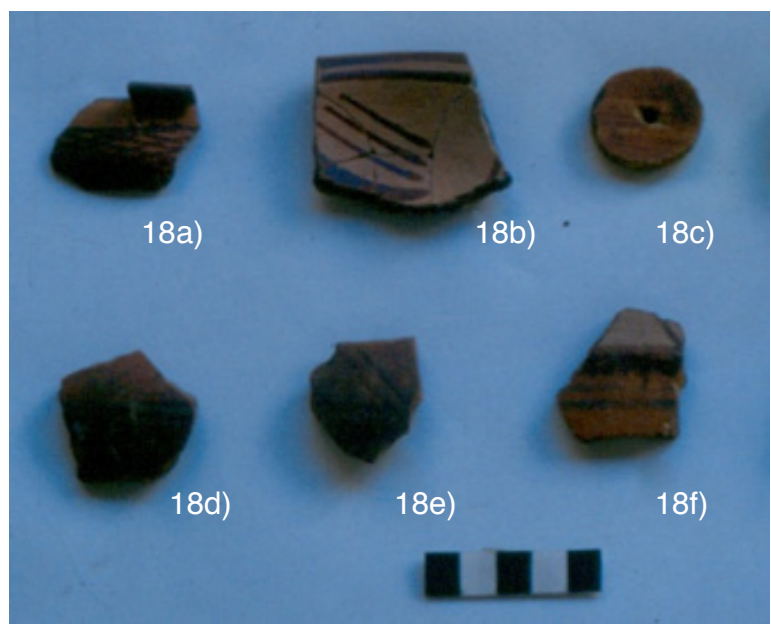

Fuente propia.

Figuras 19a), 19b) y 19c) Cerámica de filiación Quito.
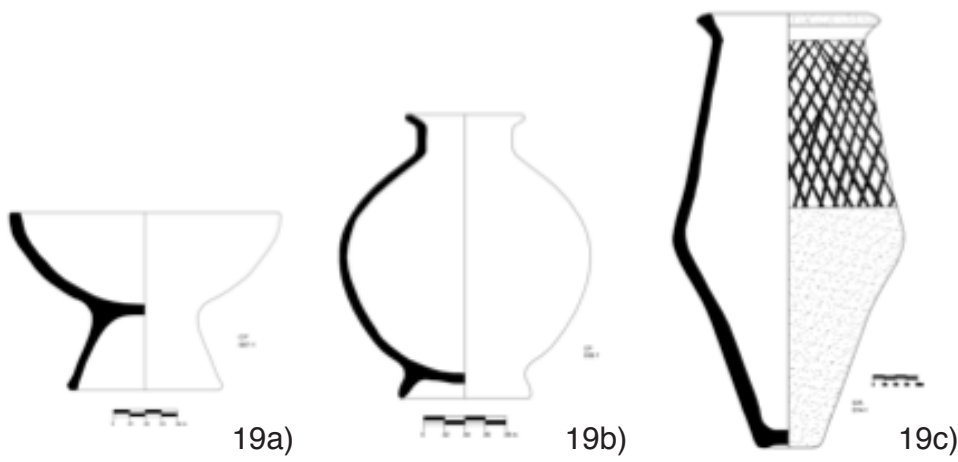

Fuente propia. 
Sobre los ladrillos usados

en la construcción del convento

En el Museo Fray Pedro Bedón, en el corredor del claustro principal y en el patio del colegio San Fernando, se han registrado ladrillos cuadrados y rectangulares con diferentes dimensiones, con un patrón de diseño diferente, y de morteros, lo que nos ha permitido establecer una tipología de ladrillos con asociación cronológica relativa. Entre los siglos XVI y XVII, la recurrencia de la medición de los ladrillos rectangulares es de 38 x $19 \times 5 \mathrm{~cm}$, con una ligera variación de 1 $\mathrm{cm}$ en algunos, lo que obedecería tal vez al molde usado y al proceso de quema de los ladrillos. También existe otro ladrillo rectangular de $31 \times 18 \times 4-5 \mathrm{~cm}$. Ambos tipos de ladrillos debieron estar asociados, entre 1595 y 1610 , en el convento de Santo Domingo, pero no se ha podido obtener información de los archivos relacionada con la compra de ladrillos para la construcción de este. Conviene resaltar que los ladrillos más grandes, que medían $38 \mathrm{~cm}$, fueron colocados para hacer la orla y los que medían $31 \mathrm{~cm}$ fueron usados en el piso espina de pez. Estos último también se usaron en el canal del tubo y el canal debajo del tercer piso y en el piso del corredor, lo que demuestra, por lo menos, su uso contemporáneo (Tabla 3).

Tabla 3. Formas de los ladrillos de los diferentes pisos.

\begin{tabular}{|c|c|c|c|c|c|}
\hline Elemento & Forma & Dimensiones (Cm.) & Fechas & Color & Siglo \\
\hline Primer piso & rectangular & $30 \times 30 \times 529 \times 39 \times 5$ & & 7.5YR 5/8 reddish yellow & $\mathrm{XIX}$ \\
\hline Segundo piso & rectangular & $42 \times 20 \times 4 \circ 5$ & 1773j/-28 A.D. & 7.5YR 4/6 strong brown & XVIII \\
\hline Tercer piso & rectangular & $31 \times 18 \times 4 \circ 5$ & & 5YR 4/6 yellowish red & XVII \\
\hline Tercer piso orla & rectangular & $38 \times 18 \times 5$ & & 5YR 4/6 yellowish red & $\mathrm{XVII}$ \\
\hline
\end{tabular}

En los siglos XVIII-XIX se usaron aparentemente de tres tipos. El tipo de ladrillos mambrones es de $2 \mathrm{~cm}$ más largo y ancho que los ladrillos del piso, y su espesor de aproximadamente el doble, quizá para soportar estructuras más fuertes. En cambio, los ladrillos empleados en la construcción de las bóvedas son más variables en el largo. A pesar de su diferencia en el uso, que quizá se debió a un cambio en el patrón de diseño de los ladrillos de fábricas diferentes, el segundo piso de ladrillo, las bóvedas y el relleno encima del tercer piso en la sala 1 del museo son contemporáneos. Finalmente, el último piso de ladrillo construido en el área de la carpintería del claustro principal debió haber sido colocado entre finales del siglo XIX y principios del XX. En este ambiente se observa que el ladrillo es de forma cuadrada con medidas de 30 × $30 \mathrm{~cm}$ y un espesor de 5 cm y está asentado simplemente sobre arena, sin un mortero especial, como se habían observado en las construcciones anteriores. 


\section{Conclusiones}

Lo interesante de este tipo de investigaciones es que permite el manejo de documentos históricos correlacionados con los datos de campo. Esta es una atrayente manera de interpretar y conocer contextos fuertemente entrelazados ya que ayuda a entender la relación prehispánica-Colonia y los procesos que se desarrollaron en torno a este sistema de colonialismo. Sin duda, este trabajo es un esfuerzo que se ofrece al mundo científico para conocer los sistemas de superposición de los que fueron objeto las sociedades precoloniales y los cambios a través del tiempo en edificaciones religiosas.

En proyectos de esta índole, el campo de la arqueología se funde con el de la arquitectura en un intento por entender la lógica de evolución cultural de una edificación. Sin embargo, más allá de esto, se hace necesario preguntarnos por los habitantes que vivieron en tiempos anteriores al proceso colonial. En el centro histórico de Quito, poco o nada se conoce sobre los asentamientos previos. A través de este tipo de investigación se ha logrado obtener mejores datos para aportar al entendimiento del patrón de asentamiento pre Colonia, durante la Colonia y su coexistencia en este último período.

La historia del convento de Santo Domingo es bastante larga y el cúmulo de datos reunidos refleja no solo la evolución histórica del predio, los cambios, las continuidades y las actividades a las que se dedicaron los monjes que habitaron en este lugar, sino también el uso anterior a la ocupación colonial. Por supuesto, aún quedan interrogantes que deben resolverse cuando se realicen más investigaciones arqueológicas dentro del casco colonial urbano y sea posible realizar comparaciones no solo del contexto sino de la cultura material colonial que hasta el momento no ha podido ser del todo caracterizada.

Sin lugar a dudas, los resultados de este tipo de investigaciones fueron de singular beneficio para los arquitectos encargados de la restauración del monumento, que en este caso formaron parte del equipo de ECUABEL. Gracias a estos trabajos se pudieron corroborar datos y esclarecer puntos de vista, y analizar las bases de una buena restauración. La revisión de los cimientos fue una tarea clave para conocer el estado de los muros y las condiciones de su estructura y controlar la humedad de los cimientos. El estudio completo constituyó un aporte de importancia para el conocimiento de esa época.

Más allá de la restauración de un monumento, la arqueología, en el marco de centros urbanos, debe darnos a conocer la evolución del conjunto o el espacio desde sus inicios y ayudar a contestar las preguntas que se plantean en la investigación para lograr un mayor conocimiento del sitio. Como se puede ver, la arqueología histórica se sistematiza y consolida a la par que cobra auge el proceso de restauración y rehabilitación del centro histórico de una ciudad. En este sentido, el registro arqueológico, dedicado a las evidencias en el subsuelo, y los registros arquitectónicos, centrados en el edificio en pie por encima del subsuelo, proporcionan datos muy relevantes sobre los procesos y cambios constructivos, que se complementan y, a su vez, se fundamentan en la información histórica que el edificio posee a través de los horizontes espacial, temporal y social. También aportan al análisis de la problemática del colonialismo, el cual intentó borrar los lugares simbólico-re- 
ligiosos de los pueblos aborígenes y, a su vez, imponer sobre estos pueblos el cambio a la religión católica con sus grandes obras, que personifican el poder de la metrópoli. Uno de los ejemplos claros de imposición evangelizadora comprende el atrio del convento, que sirvió para su proceso evangelizador.

\section{Agradecimientos}

La presente investigación formó parte de un proyecto de restauración, que contó con el financiamiento del gobierno de Bélgica y la asesoría técnica de la Cooperación Técnica de Bélgica y el Instituto Nacional de Patrimonio Cultural. Asimismo, en la dirección técnica arquitectónica, debo agradecer al arquitecto Patrick De Sutter, al licenciado Jozef Buys, director del Área de Arqueología, así como al equipo de arqueólogos, integrado por Carlos Andrade y Pilar Zambrano. Debo un especial agradecimiento a Gabriela López y a mi esposo, Gonzalo Gordon, por su colaboración en los mapas y dibujos. A María Auxiliadora Cordero, por sus valiosos comentarios y correcciones para mejorar el manuscrito, y a todos los ayudantes que formaron parte de este gran equipo de técnicos y que igualmente se capacitaron en el área de arqueología del Proyecto ECUABEL.

\section{Notas}

${ }^{1}$ Comprende una roca de origen volcánico, de característica porosa $y$ fina, compuesta por cuarzo y feldespato. En quichua significa tierra dura estéril, de color café amarillento, aunque también puede ser más oscuro. Es una formación de suelo muy común en la región interandina que aparece entre dos y cinco metros de profundidad.

${ }^{2}$ Mayólica: cerámica cubierta con una fina capa opaca de vidriado,

\section{Referencias bibliográficas}

Alemán, M. \& Van Balen, K. (1994). Puesta en valor del patrimonio arquitectónico. Quito: Libri Mundi.

Buys, J. \& Domínguez, V. (1988). Excavaciones arqueológicas en el Museo Fray Pedro Bedón, Convento de Santo Domingo de Quito. Informe técnico, Proyecto de Cooperación Técnica EcuatorianoBelga, Quito.

Buys, J., Camino, B., Santamaría, A. \& Zambrano, P. (1994). La arqueología del convento Santo Domingo. Informe final, Vol. 1. Proyecto de Cooperación Técnica Ecuatoriano Belga, Quito.

Chancay, J. (2007). Vajillas para la élite hispana: Las mayólicas del Guayaquil Temprano (1547-1690). II Congreso Ecuatoria de Antropología y Arqueología - Balance de la última década: Aportes, retos y nuevos temas (Tomo 1, pp. 283-317). Quito: Abya-Yala).

Delgado, F. \& Bravo, E. (2002). Informe final de la prospección y rescate arqueológico de la Casa del Cadisán. Presentado al Instituto Nacional de Patrimonio Cultural, Quito.

Domínguez, V. (1998a). La ocupación aborigen bajo el atrio del muy conocida en Europa entre los siglos XV al XIX. El nombre viene de la isla de Mayorca (España), de la cual obtuvo Italia estos tiestos por comercio. Generalmente se utiliza como término de clasificación tecnológica, sin referencia a sus orígenes (Heras, 1992).

${ }^{3}$ Terracota: nombre genérico para designar esculturas de barro cocido y, en general, cualquier cerámica porosa (Heras, 1992, p. 32).

convento de San Francisco de Quito. Fondo de Salvamento del Patrimonio Cultural del Municipio Metropolitano de Quito, Quito. (1998b). La excavación arqueológica en el Atrio de la Catedral de Quito. Fondo de Salvamento del Patrimonio Cultural del Ilustre Municipio de Quito, Quito.

Funari, P. P. A. (1998). Cultura material e arqueologia histórica. Campinas: Instituto de Filosifia e Ciencias Humanas-Universidade Estadual de Campinas.

Funari, P. P. A. \& Zarankin, A. (2006). Arqueología de la represión y la resistencia en América Latina (1960-1980). Buenos Aires: Brujas.

Heras, C. (1992). Glosario terminológico para el estudio de cerámicas arqueológicas. Revista Española dc Antropología Americana, 22, 9-34. Recuperado de https://revistas.ucm.es/index. php/REAA/article/view/REAA9292110009A

Iñañez, J. \& Coello J. M. (2012). La mayólica del convento Santo Domingo (Siglos XVI-XVII), Lima, Perú: La evidencia arqueolétrica. Velhos e Novos Mundos. Estudos de Arqueologia Moderna, 2, 586-846. 
Jamieson, R. (2003). De Tomebamba a Cuenca: Arquitectura y arqueología colonial. Quito: Abya-Yala.

Kennedy, A. (1989). Historia artística y arquitectónica del convento de Santo Domingo de Quito. Cooperación Técnica Ecuatoriano-Belga.

Montón, S. \& Abejez, L. (2015). ¿Qué es esa cosa llamada arqueología histórica? Complutum, 26 (1), 11-35. Recuperado de http://dx.doi.org.

Orser, C. (2000). Introducción a la arqueología histórica. Buenos Aires: Tridente.

Patiño, D. (2012). Patrimonio y arqueología histórica: Una mirada desde la Popayán colonial. Popayán: Universidad del Cauca.

Rousseau, A. (1990). Arqueología urbana: Dos casos en el Centro Histórico de Quito. En Carrión, F. et al., Centro histórico de Quito, Problemática y Perspectivas (pp. 41-54). Quito: Dirección de Planificación, Municipio de Quito.

Salomon, F. (1980). Los señores étnicos de Quito en la época de los Incas. Otavalo, Imbabura: Pendoneros.

Schávelzon, D. (1991). Arqueologia histórica de Buenos Aires: La cultura material porteña de los siglos XVIII y XIX. Buenos Aires:

\section{Corregidor.}

Senatore, M. (2000). Arqueología en Floridablanca: Plano arqueológico y espacio-social. Anales de la Academia Nacional de la Ciencias de Buenos Aires, XXIV(2), 743-753.

Terán, P. (1989). Arqueología histórica en el convento San Francisco de Quito. (Tesis inédita de grado). Centro de Estudios Arqueológicos y Antropológicos, Guayaquil.

Terán, R. (1994). Arte, espacio y religiosidad en el convento de Santo Domingo. Quito: Libri Mundi.

Ubelaker, D. (1991). Human skeletal remains from Santo Domingo. Cooperación Técnica Ecuatoriana-Belga, Quito.

Vargas, J. M. (1967). Patrimonio artístico ecuatoriano. Quito: Santo Domingo.

(1986). Historia de la provincia dominicana del Ecuador, siglos XVI y XVII. Quito: Royal.

Zarankin, A. (1995). Arqueología histórica urbana en Santa Fe La Vieja: El final del principio. Arqueología Histórica en América Latina, 10. 